\title{
Heliostat Glass Survey and Analysis
}

\author{
M. A. Lind \\ J. M. Rusin
}

September 1978

Prepared for

Sandia Laboratories

Livermore, California

under Agreement 300A0 1192

Pacific Northwest Laboratory

Operated for the U.S. Department of Energy

by Battelle Memorial Institute 


\title{
NOTICE
}

This report was prepared as an account of work sponsored by the United States Government. Neither the United States nor the Department of Energy, nor any of their employees, nor any of their contractors, subcontractors, or their employees, makes any warranty, express or implied, or assumes any legal liability or responsibility for the accuracy, completeness or usefulness of any information, apparatus, product or process disclosed, or represents that its use would not infringe privately owned rights.

The views, opinions and conclusions contained in this report are those of the contractor and do not necessarily represent those of the United States Government or the United States Department of Energy.

\author{
PACIFIC NORTHWEST LABORATORY \\ operated by \\ BATTELLE \\ for the \\ UNITED STATES DEPARTMENT OF ENERGY \\ Under Contract EY-76-C-06-1830
}

Printed in the United States of Am
Available from
National Technical Information Se
United States Department of Comr
5285 Port Royal Road
Springfield, Virginia 22151
Price: Printed Copy $\$$


PNL -2868

UC-62

33679000532079

HEL IOSTAT GLASS SURVEY AND ANALYSIS

M. A. Lind

J. M. Rus in

September 1978

Prepared for

Sandia Laboratories

Livermore, Cal ifornia

under Related Services

Agreement 300A0 1192 and

the U.S. Department of Energy

Pacific Northwest Laboratory

Richland, Washington 99352 
:

- 


\section{FOREWORD}

This report is the result of comprehensive surveys and technical analyses performed for Sandia Laboratories in support of the U.S. Department of Energy Solar Thermal Large Power Systems authorized under Sandia Livermore integrated order 92-78A54. The purpose of the survey and analysis is to provide background information and procurement specifications for materials which have potential application in heliostat construction. This report covers the work performed on the glass characterization and specification task. 
- 


\section{ACKNOWLEDGEMENTS}

The authors wish to express their appreciation to H. L. Hampton, G. P. Morgen, T. L. Stewart, M. Nordmeyer, C. Batishko and R. Bunnell (PNL) for their assistance in the glass characterization measurements and to $L$. $D$. Philipp, J. S. Hartman and L. E. Ault (PNL) for the aperture spillage calculations. They also wish to thank J. Vitko, W. Delameter, J. Shelby (SLL) and E. Beauchamp (SLA) for their many helpful technical discussions during the course of the project. Thanks are also due E. English, C. Mavis, C. Pignolet and S. Roche (SLL) for their helpful suggestions and contributions.

Finally, the authors wish to thank the many technical and administrative personnel from the glass companies listed in the Introduction for their time, assistance, and sample materials. 


\section{CONTENTS}

FOREWORD

ACKNOWLEDGEMENTS

LIST OF TABLES

LIST OF FIGURES .

INTRODUCTION

SOLAR TRANSMITTANCE OF NEW GLASS.$\quad \cdot \quad \cdot \quad \cdot \quad \cdot \quad \cdot \quad \cdot \quad \cdot \quad \cdot \quad \cdot \quad \cdot \quad \cdot \quad \cdot \quad 3$

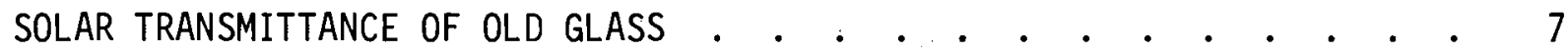

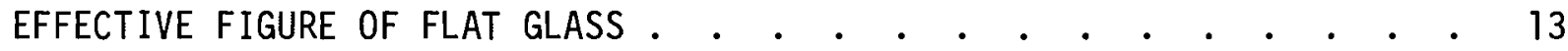

ALTERNATE TESTS FOR OPTICAL QUALITY

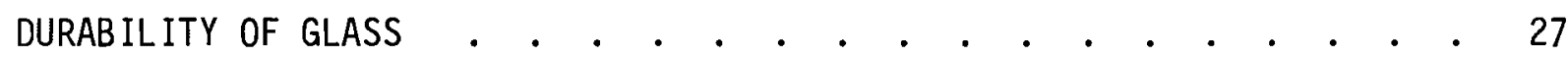

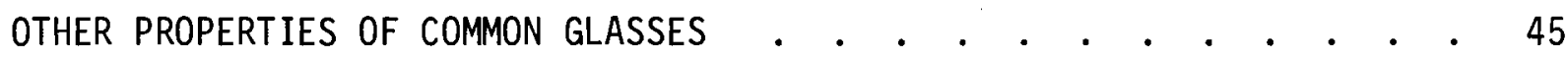

SUMMARY OF GLASS MANUFACTURER SURVEY • • • • • • • • • • • • • . . 47

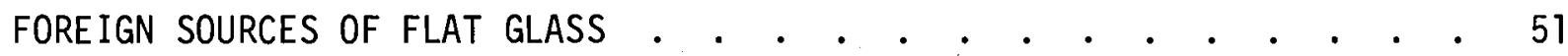

REFERENCES • • • • • • • • • • • • • • • • • • • •

APPENDIX A - Calculations of Reflectance and Transmittance for Glass and Second Surface Glass Mirrors . . . . . . . A1

APPENDIX B - Calculations of the Impact of Glass Flatness on Receiver Dimensions . . • . . . . . • . • . . B1

APPENDIX C - Foreign Manufacturers Contacted as Possible Sources of Flat Glass . • • . • . • . • • • • . . . Cl

APPENDIX D - Specification for Flat Glass for Central Receiver Heliostat Applications . • . • . • • • • • • . D D 


\section{LIST OF TABLES}

1 Typical Values for Transmission and Reflection Coefficients of Uncoated Optical Materials . . . . . . . . . . . . . 4

2 Solar Reflectance Values for Glass to Metal and Air to

Metal Interfaces . . . . . . . . . . . . . . . 5

3 Solar Transmittance of Glass . . . . . . . . . . . . . 5

4 Maximum Solar Reflectance for Second Surface Glass Mirrors . . . 6

5 Solar Transmittance of Weathered Glass . . . . . . . . . . 7

6 Solar Weighted Optical Parameters of the Hanford-D

Glass Sample.. • . . . • . . . . . . . . . . . 8

7 Leachability of Ground Glass Samples . . . . . . . . . . . 30

8 Leachability of Plate Glass Samples . . . . . . . . . . . 31

9 Linear Thermal Expansion of Selected Glasses . . . . . . . . 45

10 Physical Properties of Several Types of Glass . . . . . . . . 46

11 Glass Manufacturer Product Comparison Summary . . . . . . . . 50 


\section{LIST OF FIGURES}

1 Specular Transmittance of the Hanford-D Glass . . . . . . . . 9

2 Hemispherical Transmittance of the Hanford-D Glass . . . . . 10

3 Hemispherical Reflectance of the Hanford-D Glass . . . . . . . 11

4 Laser Raytrace Instrument for Glass Flatness Measurements . . . . 14

5 Angular Deviation from Specular Direction for First and Second Surface Reflection at $45^{\circ}$ Incidence . . . . . . . . . 15

6 Angular Deviation from Specular Direction for First and Second Surface Reflection at $45^{\circ}$ Incidence . . . . . . . . . 16

7 Comparison of the Relative Effective Glass Flatness With and Across the Draw Direction for Three Different Processing Techniques . . . . . . . . . . . . . . . . 18

8 Effective Figure of Flat Glass Used as a Second Surface Mirror . . . . . . . . . . . . . . . . . . 19

9 Effective Figure of Flat Glass Used as a Second Surface Mirror . . . . . . . . . . . . . . . . 20

10 Receiver Aperture Required to Intercept Various Amounts of the Reflected Power as a Function of Mirror Quality

11 Transmission Shadowgraph Experiment . . . . . . . . . 24

12 Comparison of Transmission Shadowgraph Intensity and Deviation in Second Surface Reflection for Fusion and Float Glass

13 Soxhlet Leach Test Apparatus . . . . . . . . . . . . . 28

14 SEM Micrographs of Reference Low Iron Plate Glass Sample 6

15 SEM Micrographs of Low Iron Plate Glass Sample 6 Soxhlet Leached for 72 Hours . . . . . . . . . . . . . . 33

16 SEM Micrographs of Low Iron Plate Glass Sample 6 $\mathrm{pH} 4$ and $\mathrm{pH} 9$ Leached . . . . . . . . . . . . . . . 34

17 Energy Dispersive X-Ray Fluorescence Analys is of Low Iron Plate Glass Sample 6 . . . . . . . . . . . . . . 35 


\section{LIST OF FIGURES (contd.)}

18 SEM Micrographs of Powdered Low Iron Glass Sample 6 Soxhlet Leached for 72 Hours . . . . . . . . . . . . 36

19 SEM Micrographs of Twin Ground Plate Glass Sample 12 Reference and Soxhlet Leached . . . . . . . . . . . 38

20 SEM Micrographs of Twin Ground Plate Glass Sample 12 Soxhlet Leached for 72 Hours . . . . . . . . . . . . . 39

21 Energy Dispersive X-Ray Fluorescence Analysis of Twin Ground Plate Glass Sample 12 . . . . . . . . . . . 40

22 SEM Micrographs of Fusion Glass Sample 7 Reference and Soxhlet Leached . . . . . . . . . . . . . . . . 41

23 Energy Dispersive X-Ray Fluorescence Analys is of Fusion Glass Sample 7 . . . . . . . . . . . . . . . . . . 42

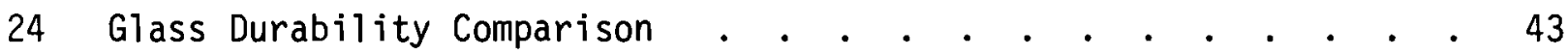

Al Air-Glass-Air Interreflection Geometry . . . . . . . . . . A2

B1 Half Angle of Receiver Aperture Required to Intercept Various Amounts of Power from Mirrors with a Rectangular Scattering Function . . . . . . . . . . . . . . . B4

B2 Half Angle of Receiver Aperture Required to Intercept Various Amounts of Power from Mirrors with a Triangular Scattering Function 


\section{INTRODUCTION}

A comprehensive survey of both foreign and domestic sources of low distortion, high transmission flat glass with a nominal thickness of $3 \mathrm{~mm}$ was undertaken. The purpose of the survey was to determine the characteristics, availability and cost of glass for use in second surface heliostat mirrors for the Barstow pilot plant and future commercial central receiver plants. Information obtained from the manufacturers and the results of investigations performed at Sandia Laboratories at Albuquerque and Livermore were compiled with the PNL characterization data to generate the specifications for the GFE glass to be used in the Barstow pilot plant.

During the course of the survey, nine of the major glass manufacturers were contacted for information and assistance. These manufacturers were PPG, Corning, Ford, LOF, CE, ASG, Fourco, Schott, and Guardian. Eleven different flat glass samples from seven of the domestic sources and one foreign source were characterized for solar transmittance, flatness and durability. The samples were representative of four different manufacturing processes: float, fusion, rolled, and twin ground. The results and implications of these glass characterization studies and a brief summary of the manufacturer survey are presented in this report. 

The solar transmittance of uncoated glass is determined primarily by the air to glass interface reflections from the surfaces of the material and absorptive losses within the material. Typical soda lime glass has a solar weighted index of refraction of about 1.52 . This yields a first surface reflectance of

$$
R_{1}=\left(\frac{1-n}{1+n}\right)^{2}=0.0426
$$

By adding the multiple reflections from the front and back surfaces of the glass (see Appendix $A$ ), the total reflectance for uncoated material is given by

$$
R=\frac{R_{1}\left(1+x^{2}-2 R_{1}\right)}{1-R_{1}^{2} \chi^{2}}
$$

Here $X$ is the internal transmittance of the material which is given by

$$
x=\exp \left(-\sum_{i} \alpha_{i} C_{i} l\right)
$$

where $\alpha_{i}$ and $c_{i}$ are the absorption coefficient and concentration of the $i^{\text {th }}$ species, and $l$ is the thickness of the material. Similarly, the transmittance is given by

$$
T=\frac{\left(1-R_{1}\right)^{2} x}{1-x^{2} R_{1}^{2}}
$$


Typical values for the transmittance and reflectance of non-absorbing glasses calculated from Equations (1-4) are shown in Table 1 for comparison purposes. These values represent the highest transmittance that one can expect to achieve without special surface treatment. Notice that the transmittance for soda lime glass is about 0.918 .

TABLE 1. Typical Values for Transmission and Reflection Coefficients of Uncoated Optical Materials

$\begin{array}{lcccc} & \text { Fused Silica } & & \text { Soda Lime } & \text { Quartz } \\ \mathrm{n} & 1.4600 & & 1.5200 & \\ \mathrm{n} & 0.0350 & & 0.0426 & 0.0460 \\ \mathrm{R} 1 & 0.0676 & & 0.0817 & 0.0889 \\ \mathrm{R} & 0.9324 & 0.9183 & 0.9111\end{array}$

If the back side of the glass has a metallic coating and is used as a second surface mirror, the reflectance becomes

$$
R=\frac{R_{1}+x^{2} R_{m}-2 R_{1} x^{2} R_{m}}{1-x^{2} R_{m} R_{1}} .
$$

Here $R_{m}$ is the glass to metal interface reflectance which can be calculated from the complex dielectric functions for the base metals or measured in the laboratory. Solar weighted values of $R_{m}$ are calculated $(1)$ for three metals and shown in Table 2. Both the reflectance of the base metal and the reflectance of the glass to metal interface are given. Notice that the reflectance at the glass to metal interface is lower than the base metal reflectance by several percent. 
TABLE 2. Solar Reflectance Values for Glass to Metal and Air to Metal Interfaces

\begin{tabular}{|c|c|c|}
\hline Metal & $\begin{array}{l}\text { Reflectance } \\
\text { Metal to Air }\end{array}$ & $\begin{array}{l}\text { Reflectance } \\
\text { Metal to Glass }\end{array}$ \\
\hline $\mathrm{Ag}$ & 0.98 & 0.97 \\
\hline $\mathrm{Al}$ & 0.92 & 0.88 \\
\hline $\mathrm{Au}$ & 0.85 & 0.82 \\
\hline
\end{tabular}

By inserting the glass to metal reflectance values into Equation (5), the reflectance of the second surface mirror can be calculated. $R_{1}$ and $X$ can be calculated from Equations (2) and (4) using measured values of $R$ and $T$. The maximum values of mirror reflectance using non-absorbing glass are very close to the glass to metal reflectance values listed in Table 2.

Glass samples collected from various manufacturers have been evaluated for solar transmittance as shown in Table 3. The specular spectral transmittance was evaluated using a Beckman 5270 spectrophotometer with an acceptance aperture of about $5^{\circ}$. The data were then solar weighted using Moon's ${ }^{(2)}$ AM2 terrestrial solar spectral distribution and a best fit interpolation routine.

TABLE 3. Solar Transmittance of Glass

\begin{tabular}{|c|c|c|c|}
\hline Manufacturer & Thickness & Process & $\begin{array}{l}\text { Solar } \\
\text { Transmittance } \\
\end{array}$ \\
\hline 1 & 0.125 & Float & 0.831 \\
\hline 2 & 0.125 & Float & 0.838 \\
\hline 3 & 0.125 & Float & 0.844 \\
\hline 4 & 0.125 & Float & 0.847 \\
\hline 5 & 0.125 & Float & 0.866 \\
\hline 6 & 0.125 & Float & 0.881 \\
\hline 7 & 0.110 & Fusion & 0.903 \\
\hline 8 & 0.090 & Fusion & 0.910 \\
\hline 9 & 0.060 & Fusion & 0.909 \\
\hline 10 & 0.125 & Rolled & 0.891 \\
\hline 11 & 0.120 & Rolled & 0.913 \\
\hline
\end{tabular}


The values of solar transmittance vary from 0.913 , which is close to the theoretical maximum, down to 0.831 depending on the glass supplier and the manufacturing process. The absorptive losses are due primarily to iron impurities in the materials. There is a broad $\mathrm{Fe}^{2+}$ absorption band centered around $1.1 \mu \mathrm{m}$ and a sharper $\mathrm{Fe}^{3+}$ band centered at $380 \mathrm{~nm}$. The solar weighted absorptance is affected most by the $\mathrm{Fe}^{2+}$ band.

In order to put these transmittance values in perspective, the maximum solar reflectivity that could be expected from second surface mirrors using these glasses has been calculated from Equation (5). Table 4 lists representative values for these quantities assuming that the glass to silver interface reflectance is $0.975^{(3)}$. Clearly, there is considerable performance improvement possible with low absorption glasses.

TABLE 4. Maximum Solar Reflectance for Second Surface Glass Mirrors

Uncoated Glass Solar Transmittance

0.910

0.840
Silvered Second Surface Mirror Solar Reflectance
0.880

0.958

0.896

0.818 


\section{SOLAR TRANSMITTANCE OF OLD GLASS}

In order to assess the effects of weathering on the transmittance of glass, several old samples were collected from two desert environments for evaluation. The glass obtained by PNL at the Hanford reservation in Washington came from south-facing, vertical windows which were known to be over forty years old. The glass obtained by Sandia from Barstow, California is estimated to be over twenty years old ( $S$. Roche, personal communication).

The samples all contained areas that were covered from exposure by the window framing material. It was thus possible to compare the exposed and presumably unexposed areas of the glass. Table 5 lists the various values of the solar transmittance of unexposed glass as $T_{S}$. The relative difference in transmittance of the exposed areas is given as $\Delta \mathrm{T}_{\mathrm{S}}$.

TABLE 5. Solar Transmittance of Weathered Glass

$\begin{array}{ccc} & I_{S} \text { (Unexposed) } & \Delta T_{S} \text { (Expos } \\ \text { HANFORD GLASS } & & \\ \text { Sample A } & 0.865 & -0.019 \\ \text { Sample B } & 0.864 & -0.022 \\ \text { Sample C } & 0.839 & -0.007 \\ \text { Sample D } & 0.861 & -0.001 \\ \text { BARSTOW GLASS } & & \\ \text { Sample A } & 0.900 & +0.005 \\ \text { Sample B } & 0.841 & +0.011 \\ \text { Sample C } & 0.845 & +0.005\end{array}$

The differences between the exposed and unexposed areas are generally less than two percent. The spectral transmittance of the exposed areas of al1 the samples measured was characterized by a fairly large loss of transmittance in the UV-visable and an increase in the near infrared. Although the specularity of the samples was not measured, visually they a 11 appeared 
fairly clear and free of surface contamination and abrasion. The only definitive conclusion that can be drawn from the scattered data is that the effects of weathering appear to be small.

One of the Hanford samples (D) was more carefully characterized in order to determine if the changes in the solar transmittance were due to surface or bulk effects. SEM micrographs were taken of both the exposed and unexposed areas to look for changes in the surface morphology. Some differences were observed but nothing extreme. The exposed area away from the frame edge has a slightly rougher surface texture than the unexposed area. The area immediately adjacent to the frame edge showed significant texture. This is possibly due to additional l leaching of the glass from longer moisture contact near the frame edge.

In addition, normal hemispherical reflectance and transmittance measurements were performed. The results are shown in Table 6. Although there was very little change in the specular transmittance, the hemispherical transmittance of the exposed area increased markedly. Both the solar reflectance and absorptance decreased correspondingly.

TABLE 6. Solar Weighted Optical Parameters for the Hanford-D Glass Sample

\begin{tabular}{|c|c|c|c|c|}
\hline & $\begin{array}{c}\text { Specular } \\
\text { Transmittance }\end{array}$ & $\begin{array}{l}\text { Hemispherical } \\
\text { Transmittance }\end{array}$ & $\begin{array}{l}\text { Hemispherical } \\
\text { Reflectance } \\
\end{array}$ & $\begin{array}{l}\text { Calculated } \\
\text { Absorptance }\end{array}$ \\
\hline Unexposed & 0.861 & 0.860 & 0.067 & 0.073 \\
\hline Exposed & 0.860 & 0.891 & 0.055 & 0.054 \\
\hline Change & 0.001 & +0.031 & -0.012 & -0.019 \\
\hline
\end{tabular}

The spectrophotometer curves which have been corrected for offset and gain are shown in Figures 1-3. The difference curves are also included. The hemispherical, like the specular, transmittance is characterized by an increase in transmittance in the exposed area in the near infrared and a decrease in the blue. The crossover point is shifted from about $700 \mathrm{~nm}$ for the specular curve to about $480 \mathrm{~nm}$ for the hemispherical curve. 

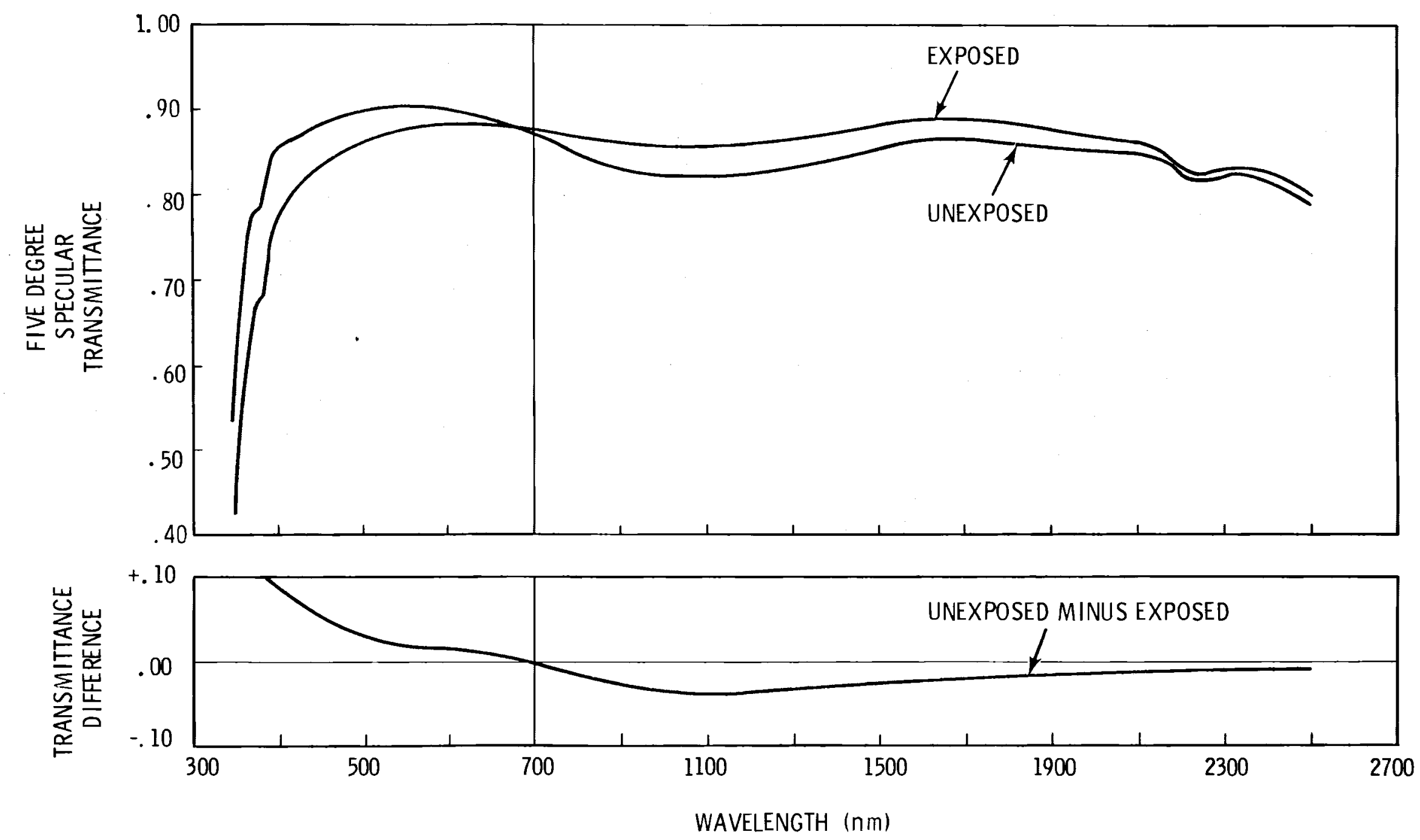

FIGURE 1. Specular Transmittance of the Hanford-D Glass 


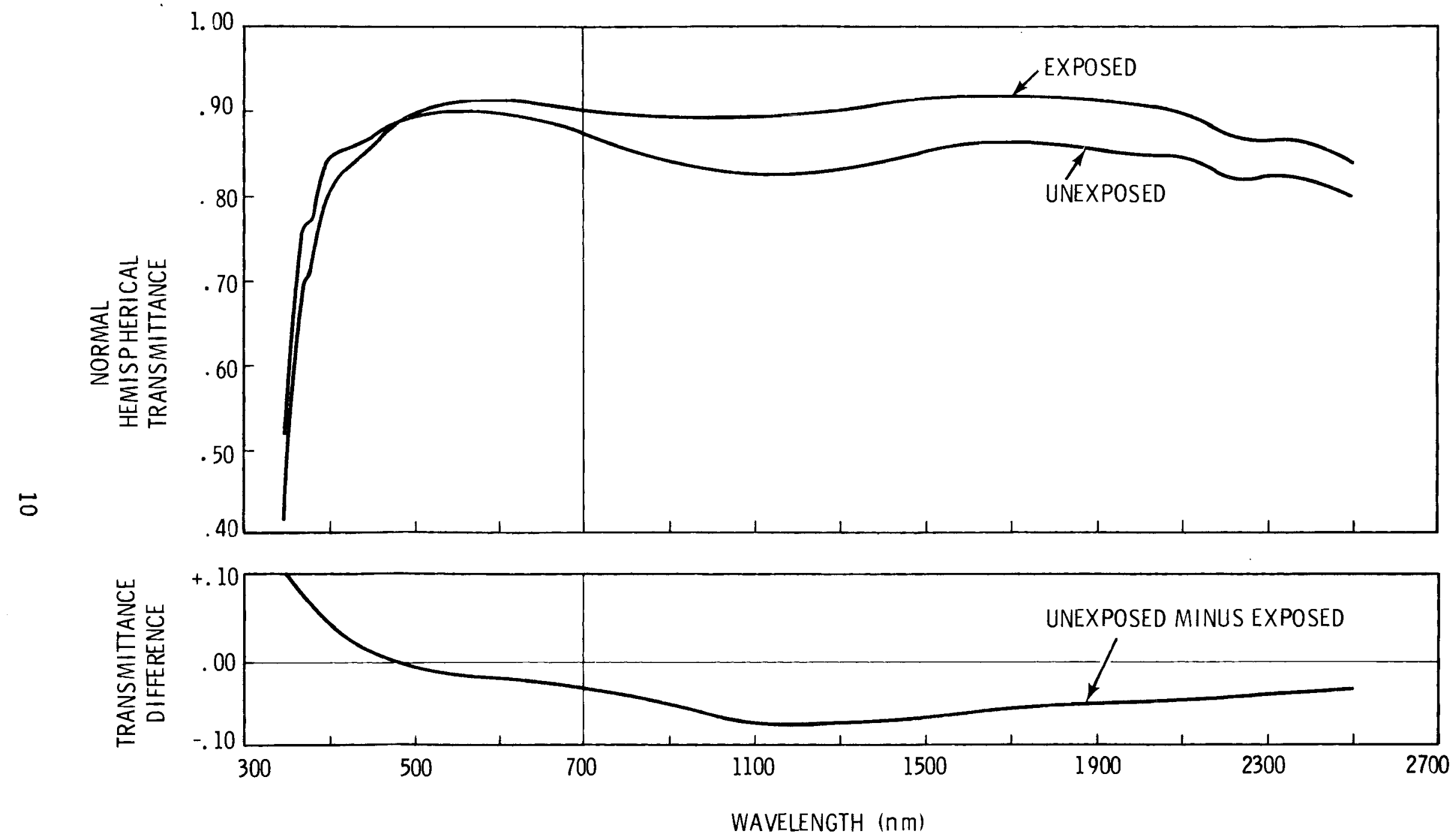

FIGURE 2. Hemispherical Transmittance of the Hanford-D Glass 

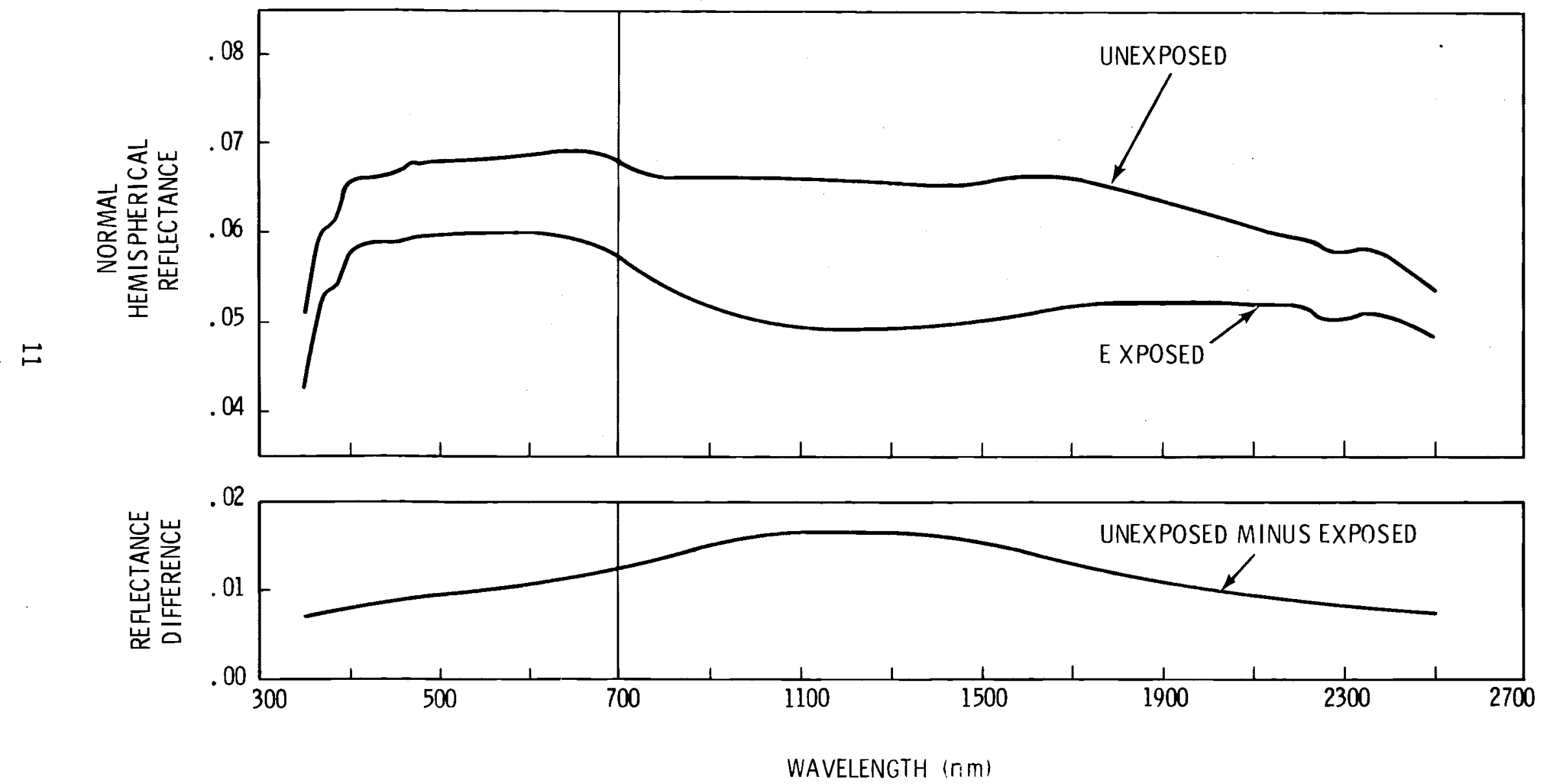

FIGURE 3. Hemispherical Reflectance of Hanford-D Glass 
The broad $\mathrm{Fe}^{2+}$ absorption band at $1100 \mathrm{~nm}$ has diminished in intensity in the exposed area. The magnitude of the reflectance decrease at $1100 \mathrm{~nm}$ is not sufficient to account for the transmission increase. It is therefore reasonable to assume that the concentration of $\mathrm{Fe}^{2+}$ has decreased. It has been suggested that solarization could raise the oxidation state of the iron from the $2+$ to the $3+$ state, thus increasing the absorption around $380 \mathrm{~nm}$. Although the data support this thesis, the results are not conclusive. Further measurements are required to determine the exact mechanisms for the observed changes. It is clear, however, that changes in transmittance are due to both surface and bulk effects. 


\section{EFFECTIVE FIGURE OF FLAT GLASS}

The effective figure or flatness of float, fusion and rolled glass was measured using the laser raytrace instrument shown schematically in Figure 4. In the instrument, a laser beam is directed onto the glass sample at $45^{\circ}$ from the surface normal. Either the first or second surface reflection may be blocked to allow examination of the desired surface. The reflected beam is intercepted by a single axis linear position sensing diode. This silicon diode coupled with appropriate electronics provides an analog signal that is proportional to the displacement of the centroid of the laser beam from a preset null point. The output signal is then calibrated in terms of the angular displacement of the laser beam from the specular direction.

The glass sample is placed on a ground flat table which is smoothly translated on linear bearings by a ball screw coupled to a small motor. The position of the table is monitored with another small laser reflected from a fixed mirror onto a second position sensitive diode. The output from both diodes drives a conventional $X Y$ recorder to produce plots of position versus the effective optical flatness of the sample. It should be noted that the angle of deviation in the optical reflection will be twice as large as the wedge angle in the glass sample.

Samples for evaluation were solicited from the major U.S. glass manufacturers. The samples are thought to be representative of the lines from which they were taken. In each case, the samples were from a $30 \mathrm{~cm}$ wide strip cut across the entire width of the glass line. The strip was then sectioned into 18 to 24 inch segments for transportation and measurement.

Figures 5 and 6 are representative traces from the actual output of the instrument. Both the first and second surface reflections are shown. The traces are pieced together from a series of shorter segments of the individual samples. The traces show graphically the effective flatness of both sides of the glass as the laser beam is translated across the draw direction of the glass line. 

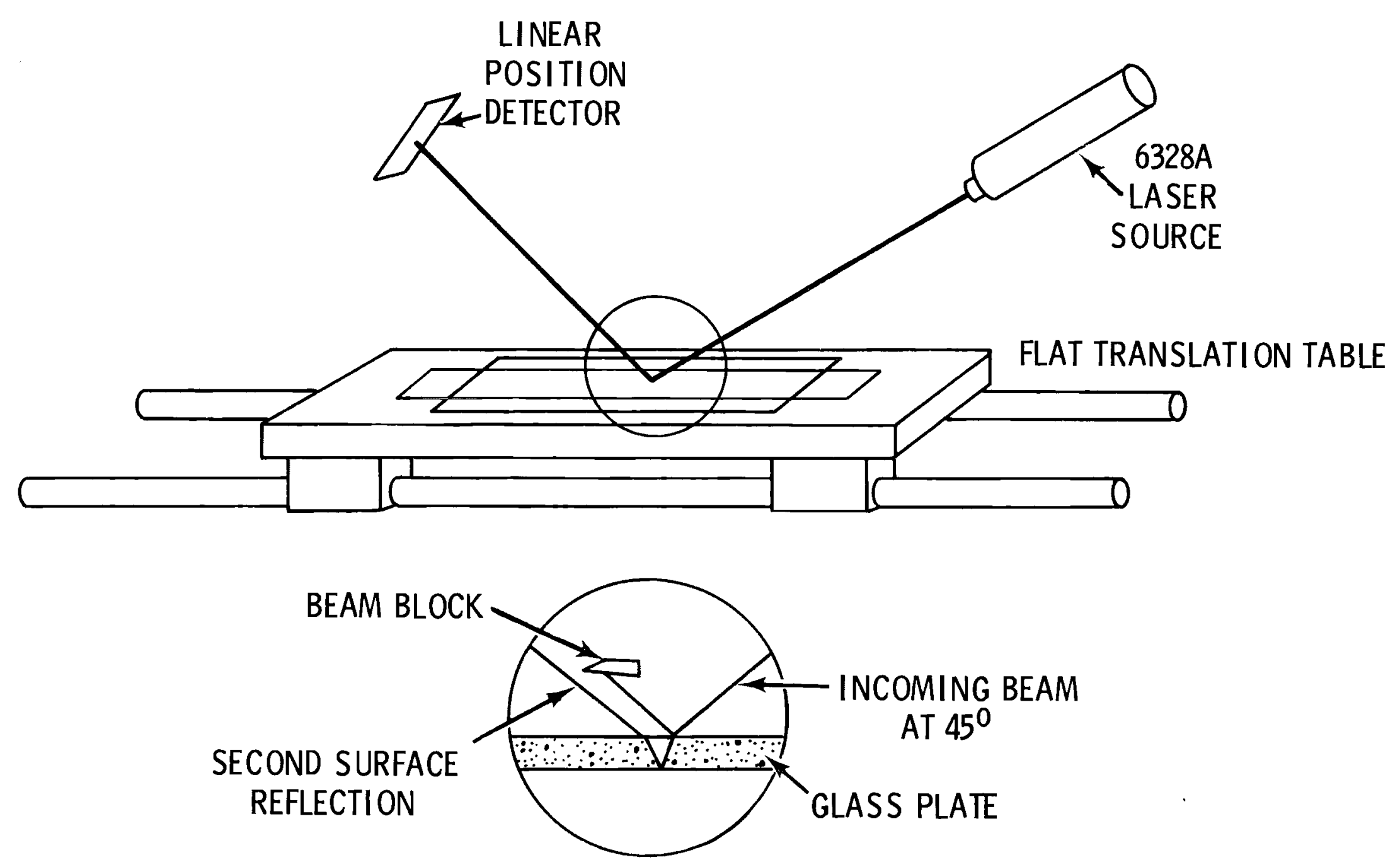

FIGURE 4. Laser Raytrace Instrument for Glass Flatness Measurements 

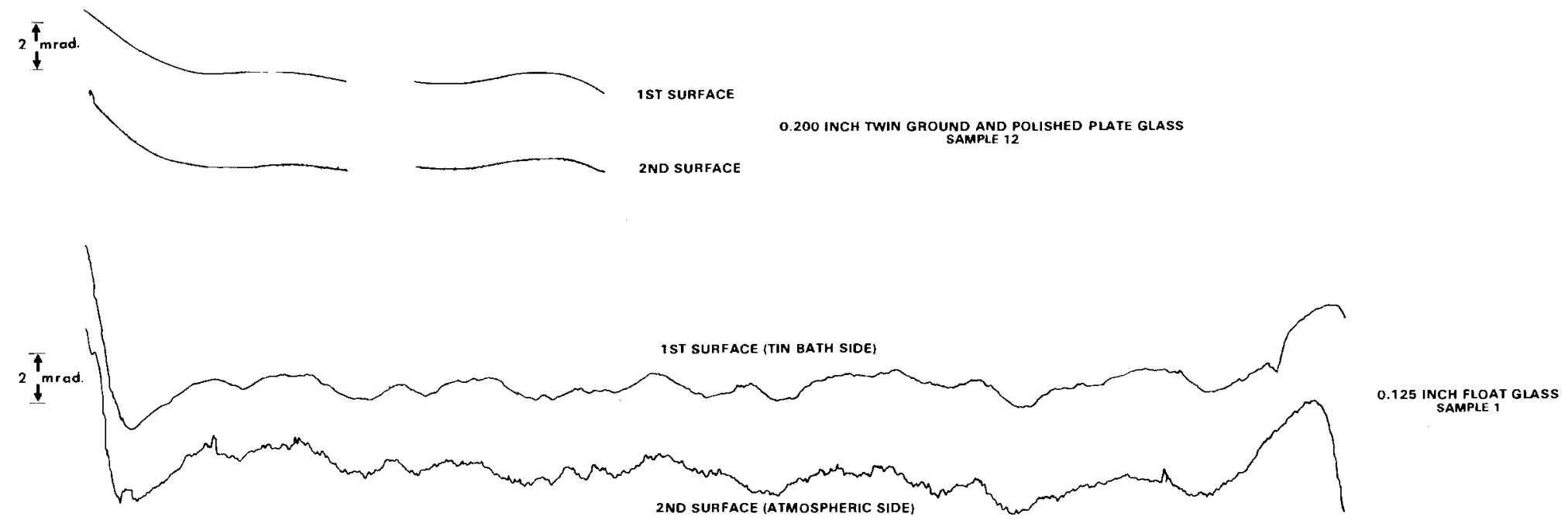

जे
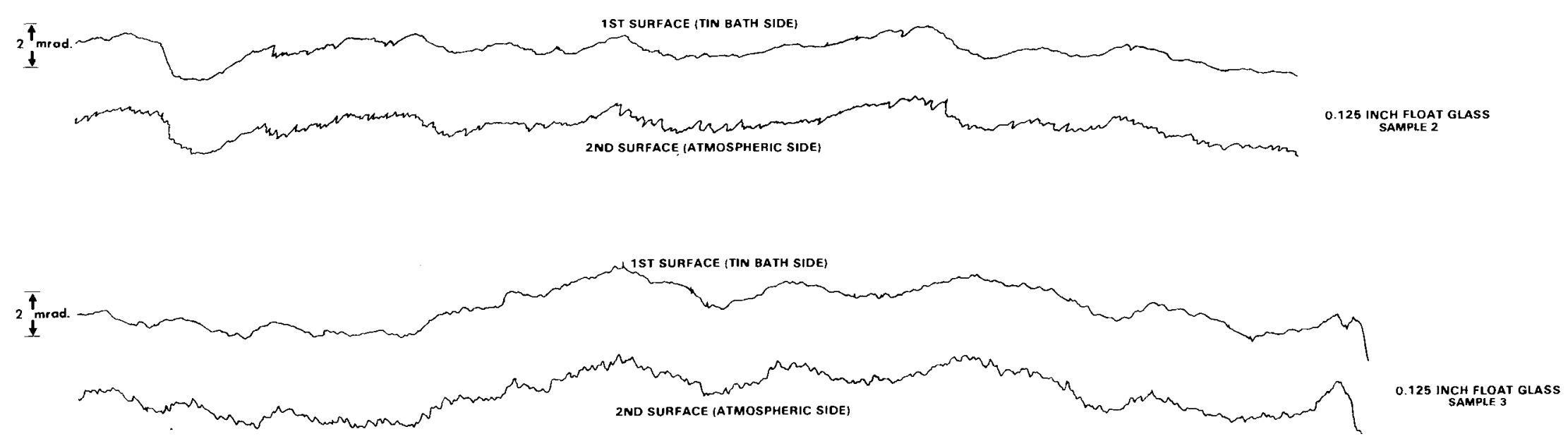

FIGURE 5. Angular Deviation from Specular Direction for First and Second Surface Reflection at $45^{\circ}$ Incidence 


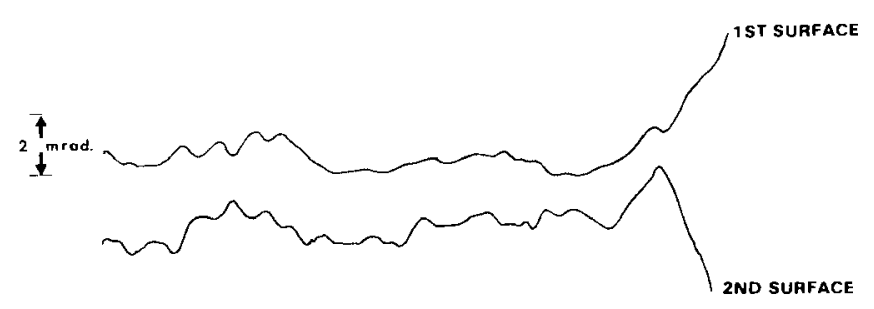

0.090 INCH FUSION GLASS
SAMPLE 8

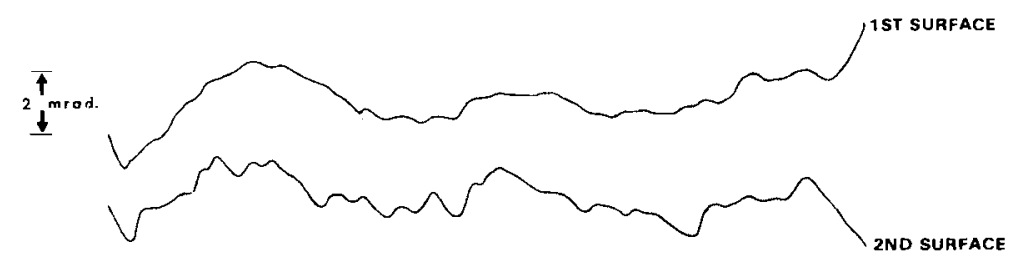

0.110 INCH FUSION GLASS

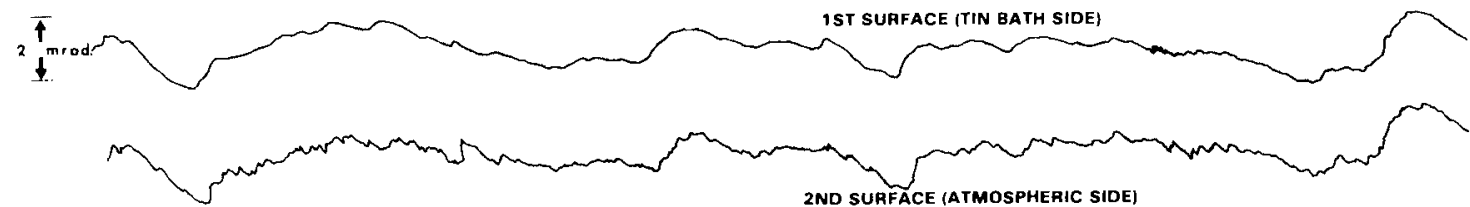

IND SUARACE (ATMOSPHERIC SIDE)

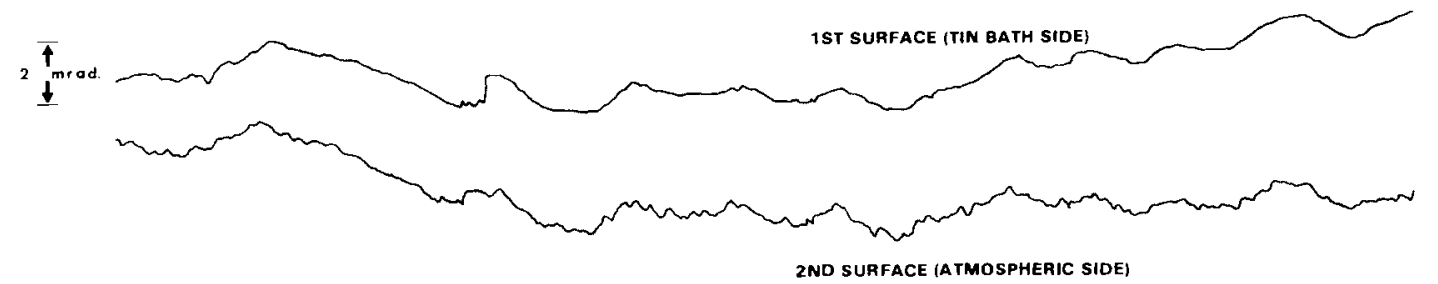

3 mm FLAAT GLASS
SAMPLE 6

FIGURE 6. Angular Deviation from Specular Direction for First and Second Surface Reflection at $45^{\circ}$ Incidence 
The traces show clearly that the twin ground and polished plate, Sample 12 in Figure 5, is much flatter than the other glasses. The gaps in the curve are the result of a missing segment. The float glass is all very similar in nature. Both surfaces parallel one another closely as verified by an additional set of first surface reflection measurements. There is also no noticeable difference in flatness of the tin bath side versus the atmospheric side. The smaller features in the second surface reflection can be attributed to bulk inhomogeneities causing index changes in the glass rather than surface roughness.

The fusion glass, Samples 7 and 8 in Figure 6 , has a slightly different character. The irregularities from the second surface reflection have a longer period than those in the float glass. This behavior is characteristic of the fusion process.

All the glass examined is an order of magnitude flatter in the direction of the draw than it is across the draw. This is shown graphically by the second surface laser raytrace curves in Figure 7 . Samples representative of all three processing techniques show the same behavior.

The results of the laser raytrace measurements are summarized in Figures 8 and 9. The plots show the fraction of the glass area that reflects light outside of a specified angular deviation. For example, the upper curve in Figure 8 shows that $60 \%$ of the light would deviate from the specular direction by more than \pm 2.0 milliradians. Two additional factors should be considered when comparing the curves. The glass is in a horizontal position on a flat tabie and it conforms slightly to the shape of the table under its own weight. This gravitational effect is represented in the raw data. An additional correction of up to one milliradian per foot has been subtracted from the raw data to el iminate the effects of long wavelength irregularities in the glass. This slight correction is typical of the magnitude of the irregularities that might be removed during a lamination or substrate adhesion process without generating large internal stresses in the glass. 

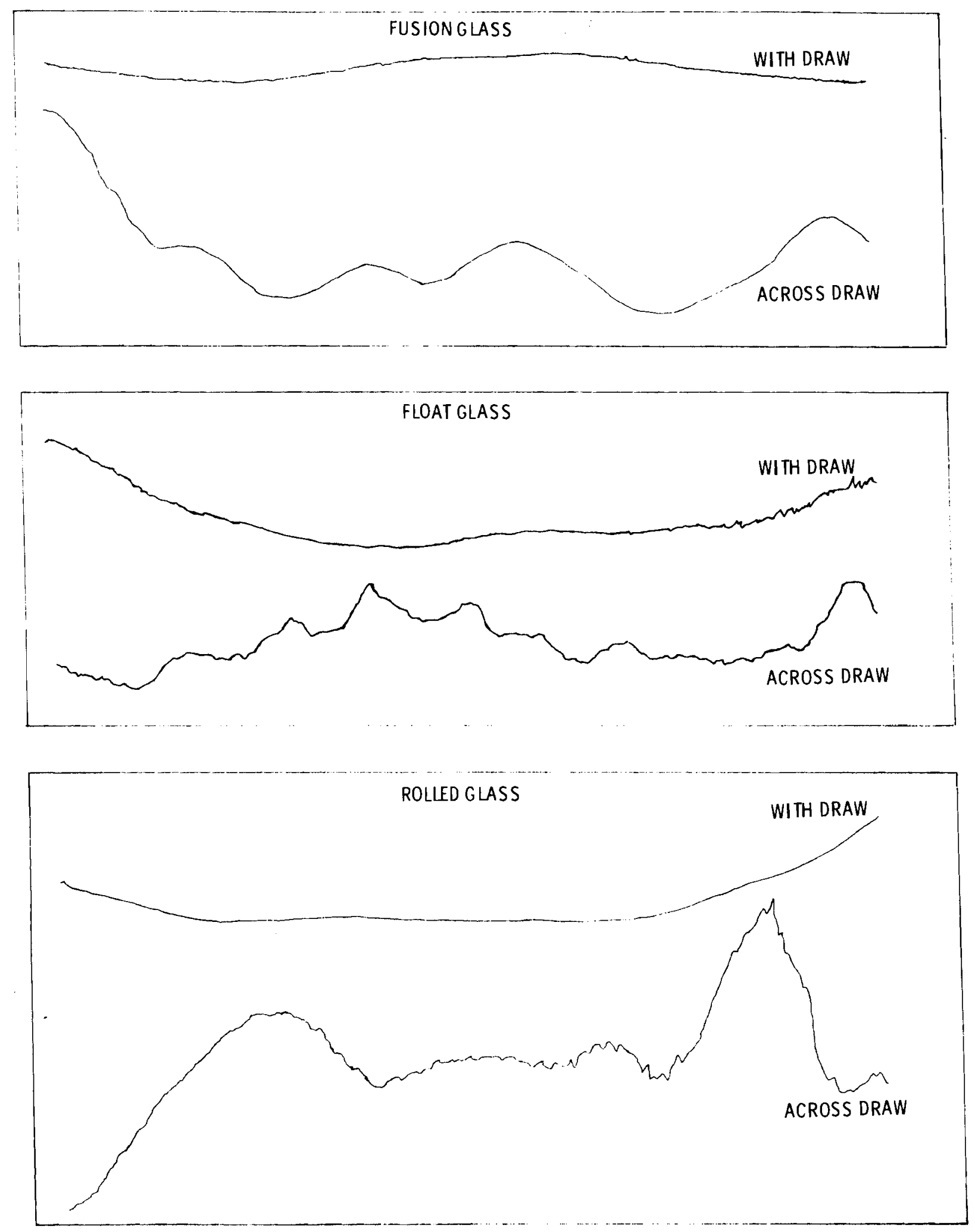

FIGURE 7. Comparison of the Relative Effective Glass Flatness With and Across the Draw Direction for Three Different Processing Techniques. (The three diagrams are not drawn to the same vertical scale.) 


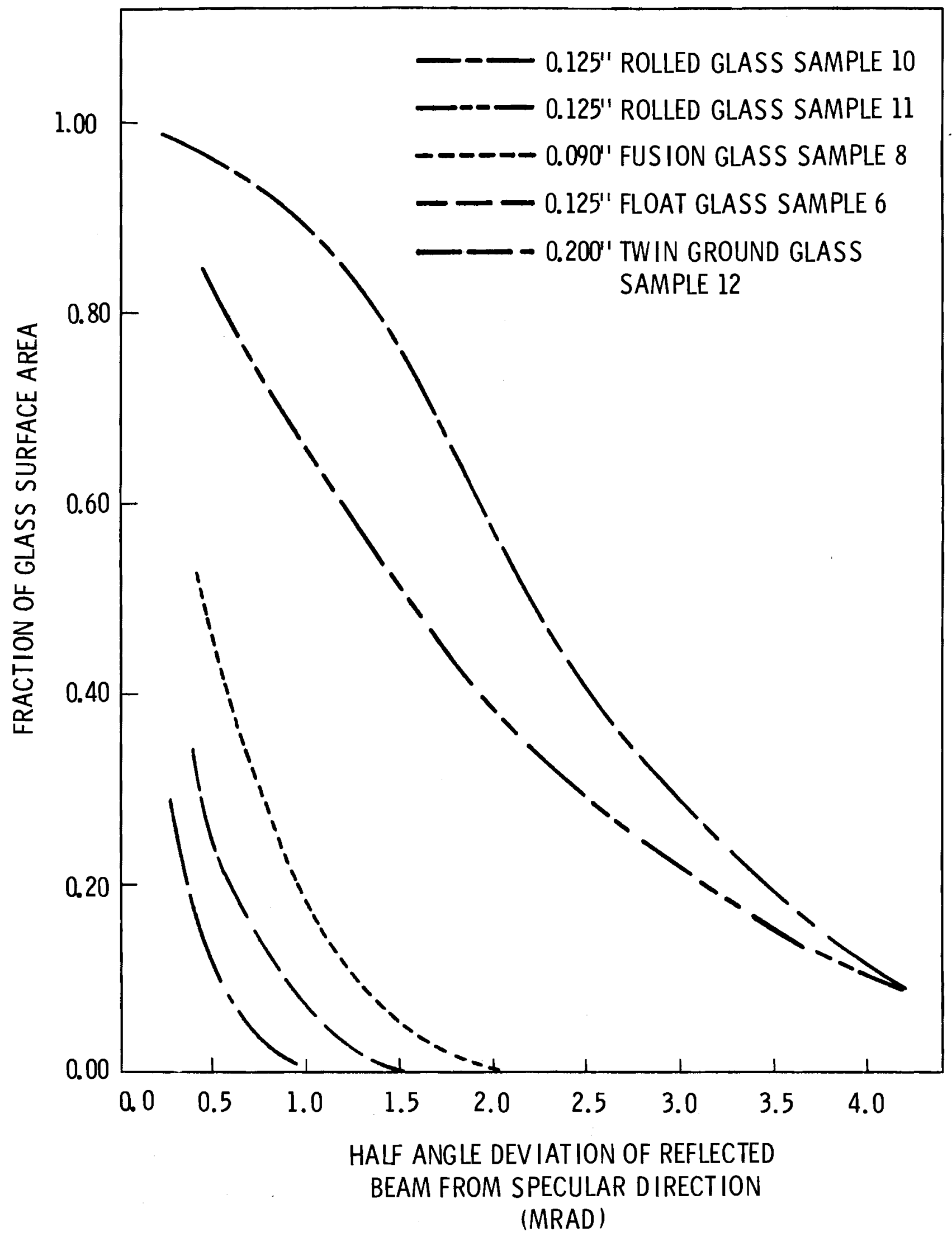

FIGURE 8. Effective Figure of Flat Glass Used as a Second Surface Mirror 


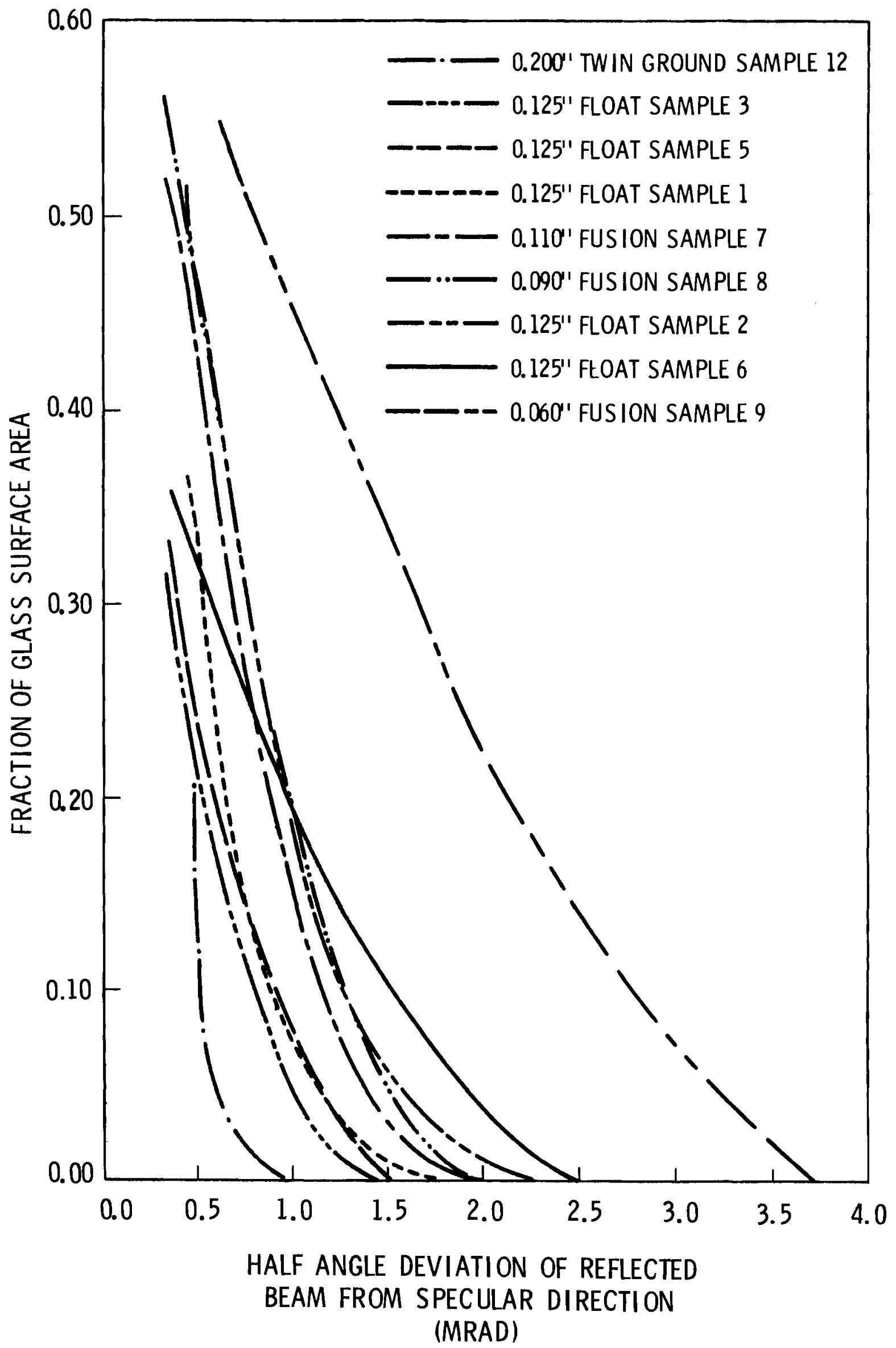

FIGURE 9. Effective Figure of Flat Glass Used as a Second Surface Mirror 
Figure 8 shows that both rolled glass samples are considerably less flat than the fusion and the float glass samples. Again, the twin ground sample has the flattest surface of the samples examined.

Figure 9 compares the float and fusion glass samples that were examined. Except for the 0.060" fusion glass, all the samples showed deviations of less than \pm 2.5 milliradians. The manufacturer of the 0.060 " fusion glass has indicated that the increase in waviness is not typical of the line capabilities.

The information contained in the curves in Figures 8 and 9 can be used to estimated the impact of the surface waviness on the power spillage at the receiver. Calculations have been performed which place a conservative estimate on the angular aperture of the receiver required to intercept various amounts of the power reflected from mirrors constructed of glass with scattering characteristics similar to those measured above. The results of the calculations are shown in Figure 10. Details of the calculation and the assumptions are given in Appendix B. The bands represent the range of values for the maximum receiver dimension in the scattering direction in order to intercept a given fraction of the reflected power. Using the curves one can see that for glass with a maximum half-width scattering angle of $2.5 \mathrm{mrad}$, a rectangular receiver would need an angular aperture somewhere between $9.5 \times$ 9.5 and $10.5 \times 9.5$ milliradians to intercept $95 \%$ of the reflected energy. 


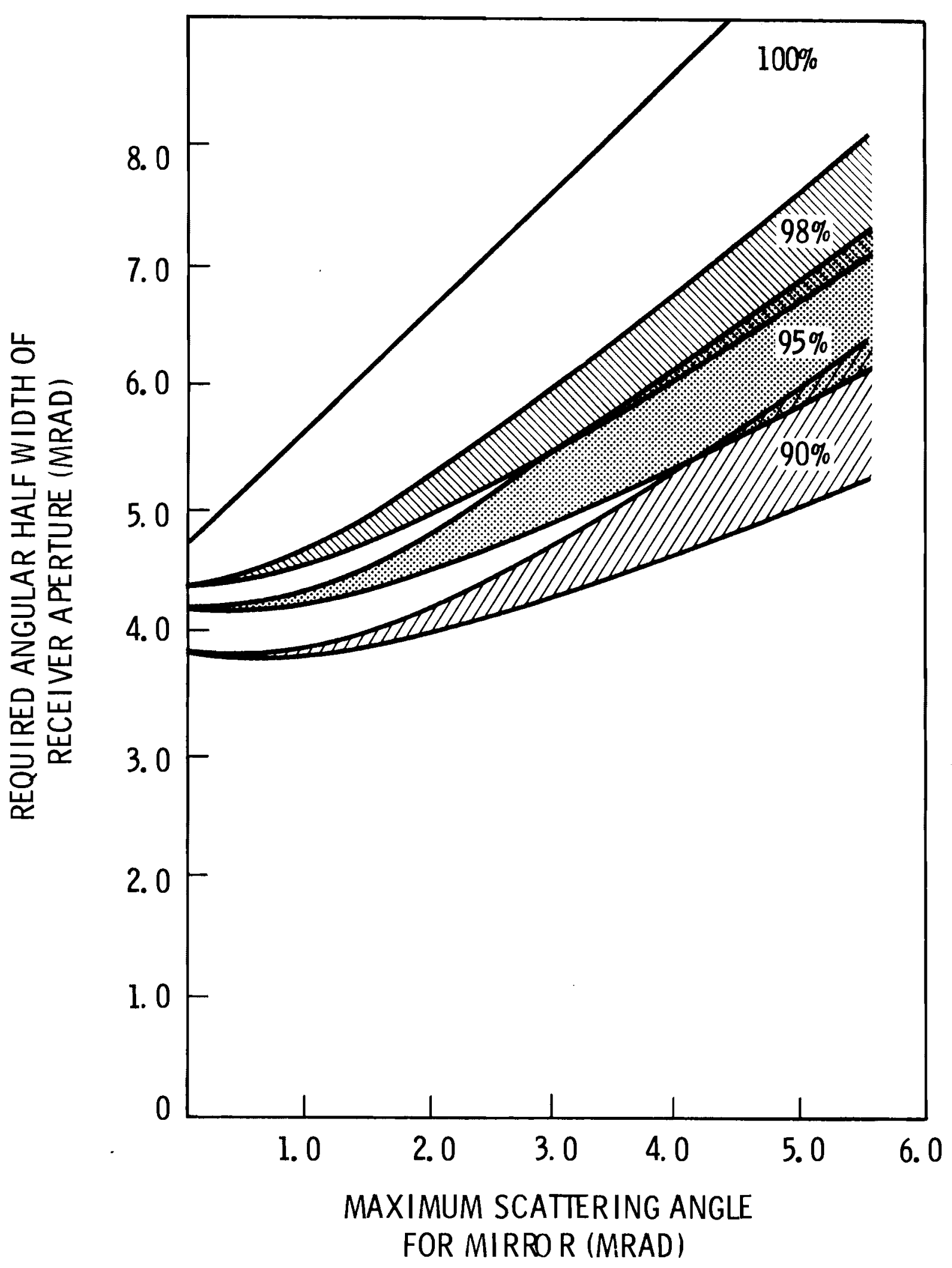

FIGURE 10. Receiver Aperture Required to Intercept Various Amounts of the Reflected Power as a Function of Mirror Quality 


\section{ALTERNATE TESTS FOR OPTICAL QUALITY}

The glass industry has several standard methods of judging the optical quality of sheet glass. The laser raytrace method described in the previous section is not one of them. A series of experiments were performed to determine if any of the standard industry tests could be used to screen glass for heliostat applications.

The tests considered are described in detail in Appendix D. These were the "Zebra" or "vision interference angle" tests (4b), the "inch" test (4c), and the "shadowgraph" test $(4 \mathrm{c})$. It was found experimentally that the test which showed the highest degree of correlation to the laser raytrace experiment was a combination of all three.

A transmission shadowgraph experiment was set up in which a semicollimated light source ( $25^{\circ}$ divergence) was directed across a translation table as shown in Figure 11. The angle between the optic axis of the system and the normal to the glass was designated $\theta_{z}$. A slit aperture and detector was placed approximately one meter behind the center of the glass. The glass was then translated across the light path. The output of the detector was recorded as a function of the table position.

The output from the position readout was appropriately scaled to account for the angle of the glass and the results compared with the laser raytrace experiment. The best runs for both float and fusion glass are shown in Figure 12. While some correlation between the two methods does exist, there is not a one-to-one correspondence between the two techniques. 


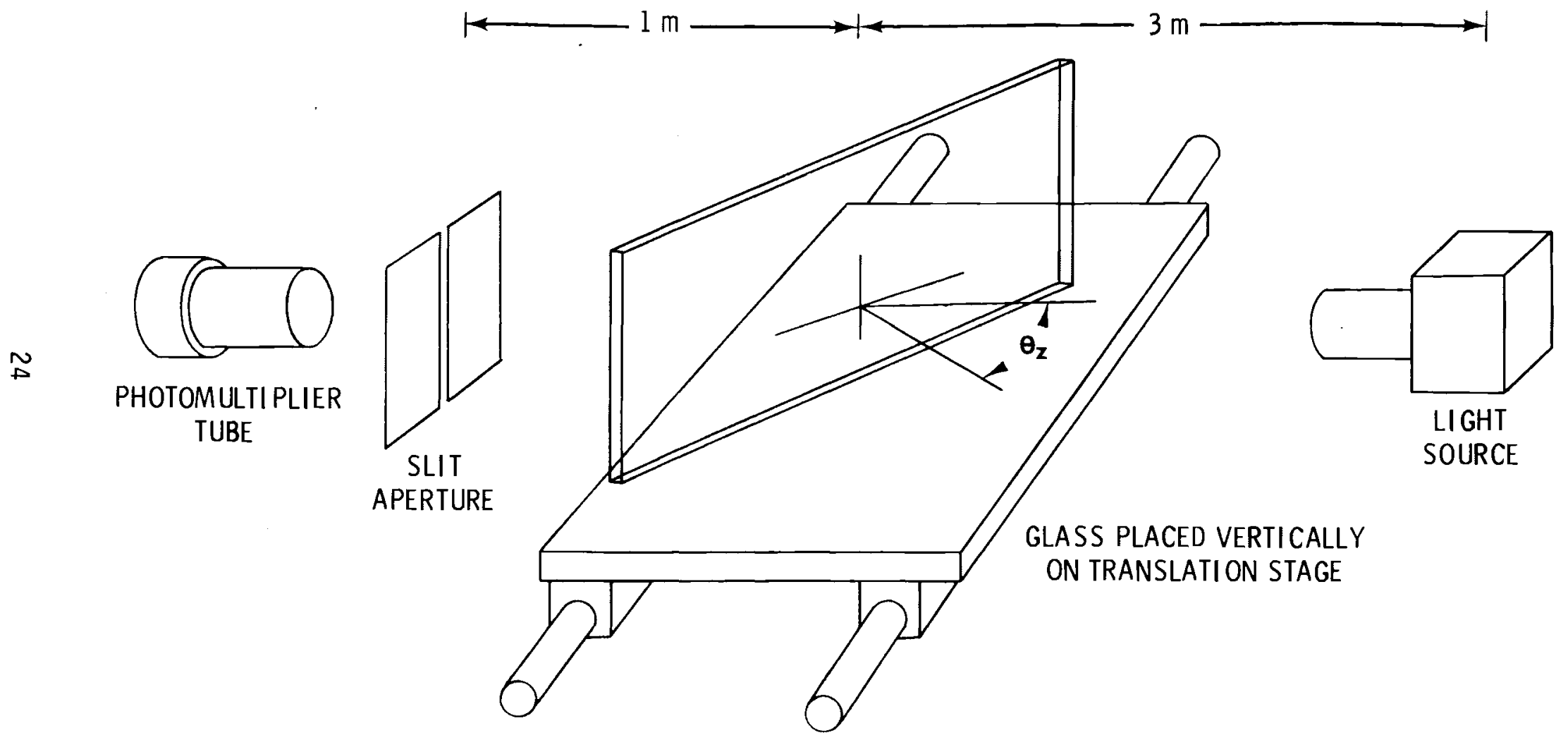

FIGURE 11. Transmission Shadowgraph Experiment 


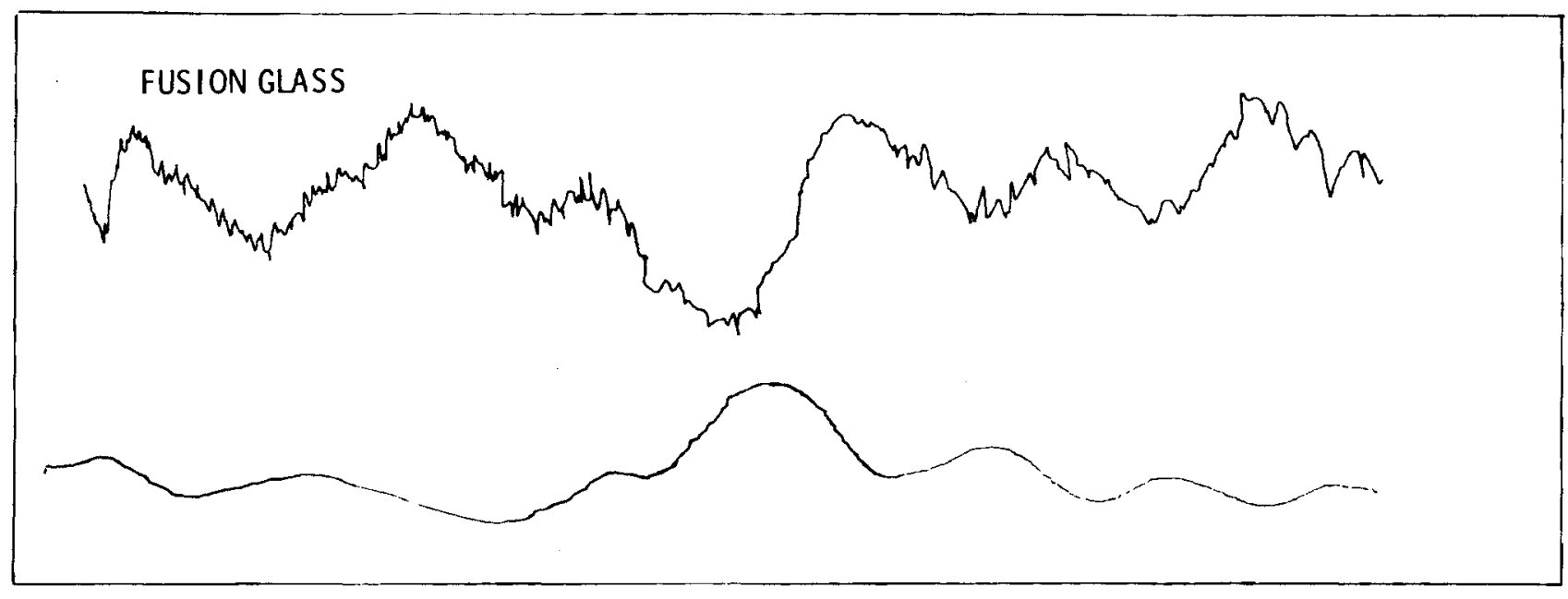

TRANSMISSION

SHADOWGRAPH

INTENSITY SCAN

$\theta_{Z}=45^{\circ}$

DEVIATION IN SECOND SURFACE REFLECTION AT $45^{\circ}$ INCI DENCE

$\tilde{N}$

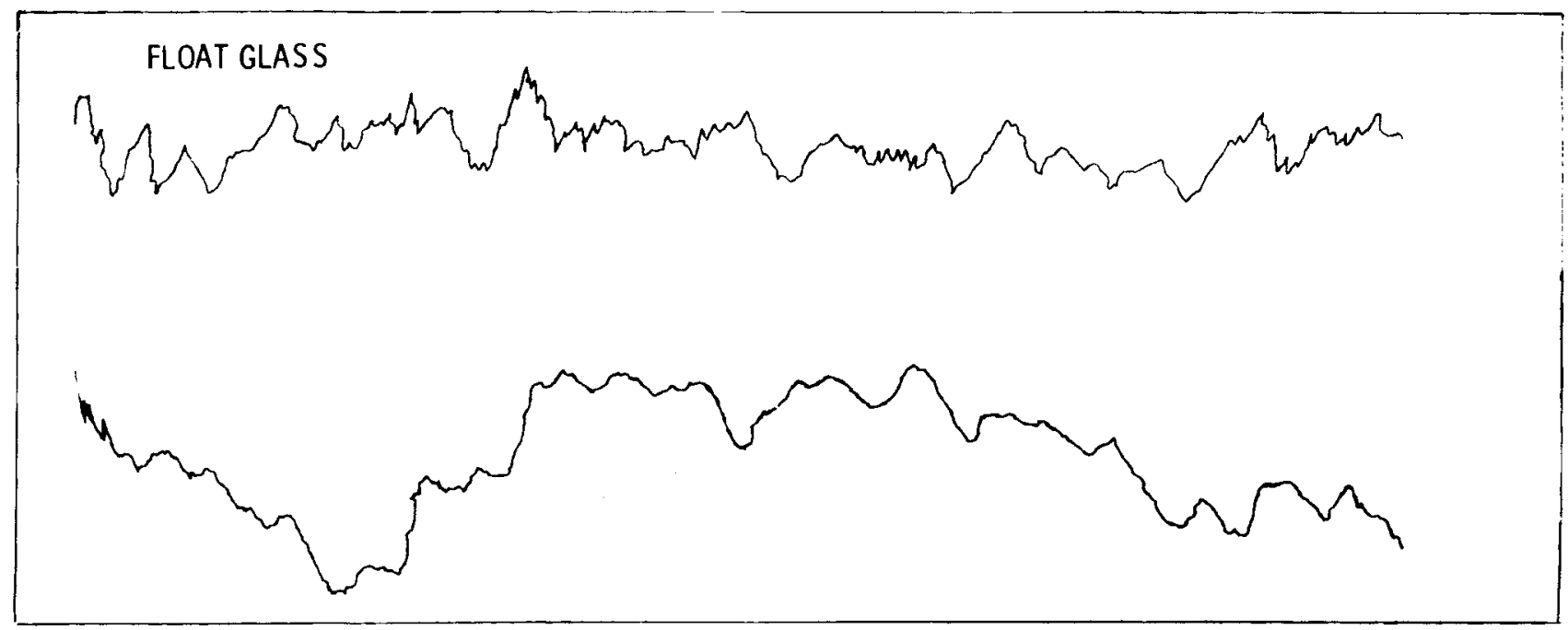

TRANSMISSION

SHADOWGRAPH

INTENSITY SCAN

$\theta_{Z}=60^{\circ}$

DEVIATION IN SECOND

SURFACE. REFLECTION

AT $45^{\circ}$ I NCI DENCE

FIGURE 12. Comparison of Transmission Shadowgraph Intensity and Deviation in Second Surface Reflection for Fusion and Float Glass 


\section{.}




\section{DURABILITY OF GLASS}

To determine the durability of glasses proposed for heliostat mirrors, selected samples were leached in a Soxhlet apparatus and pH 4 and pH 9 buffer solutions. The glass samples produced by the float process are soda-limesilica glasses, whereas the glass samples produced by the fusion process are aluminosilicate glasses.

Two basic types of sample configurations are used. One was a piece of the "as-received" plate cut $21 / 2 \times 1 / 2-i n$. The other type of sample consisted of crushed glass plate, screened to $-40+60$ mesh (U.S. Standard). The crushed glass has greater surface area than the plate sample $\left(200-300 \mathrm{~cm}^{2} / \mathrm{g}\right.$ vs $2-4 \mathrm{~cm}^{2} / \mathrm{g}$ ) and thus is used for obtaining accelerated results.

The Soxhlet test operates at $95^{\circ} \mathrm{C}$ and the sample, which is contained in a stainless steel bag, is exposed to redistilled water every 3 min., as illustrated in Figure 13. The pH 4 buffer solution is made from ammonium hydroxide and ammonium chloride and the $\mathrm{pH} 9$ from sodium acetate and acetic acid. The $\mathrm{pH} 4$ and $\mathrm{pH} 9$ tests are at room temperature and the sample is contined in a stainless steel bag. The solutions are contained in plastic bottles which are agitated by a shaker machine.

The Soxhlet test is an accelerated test that is useful for general comparison and ranking of glasses. This test is not characteristic of heliostat environmental conditions. The room temperature, $\mathrm{pH} 4$ and $\mathrm{pH} 9$ buffer leach tests may be more representative of actual heliostat conditions. These tests simulate the attack of acidic or basic environments under static conditions.

There are two general mechanisms of corrosion or leaching of solids. The first follows the square root of time, $t^{1 / 2}$, and represents a region of selective ion leaching and silica gel formation. The second leaching mechanism has kinetics directly proportional to time, $t^{1}$, and represents dissolution of the silica gel region and/or bulk leaching. Since only one 


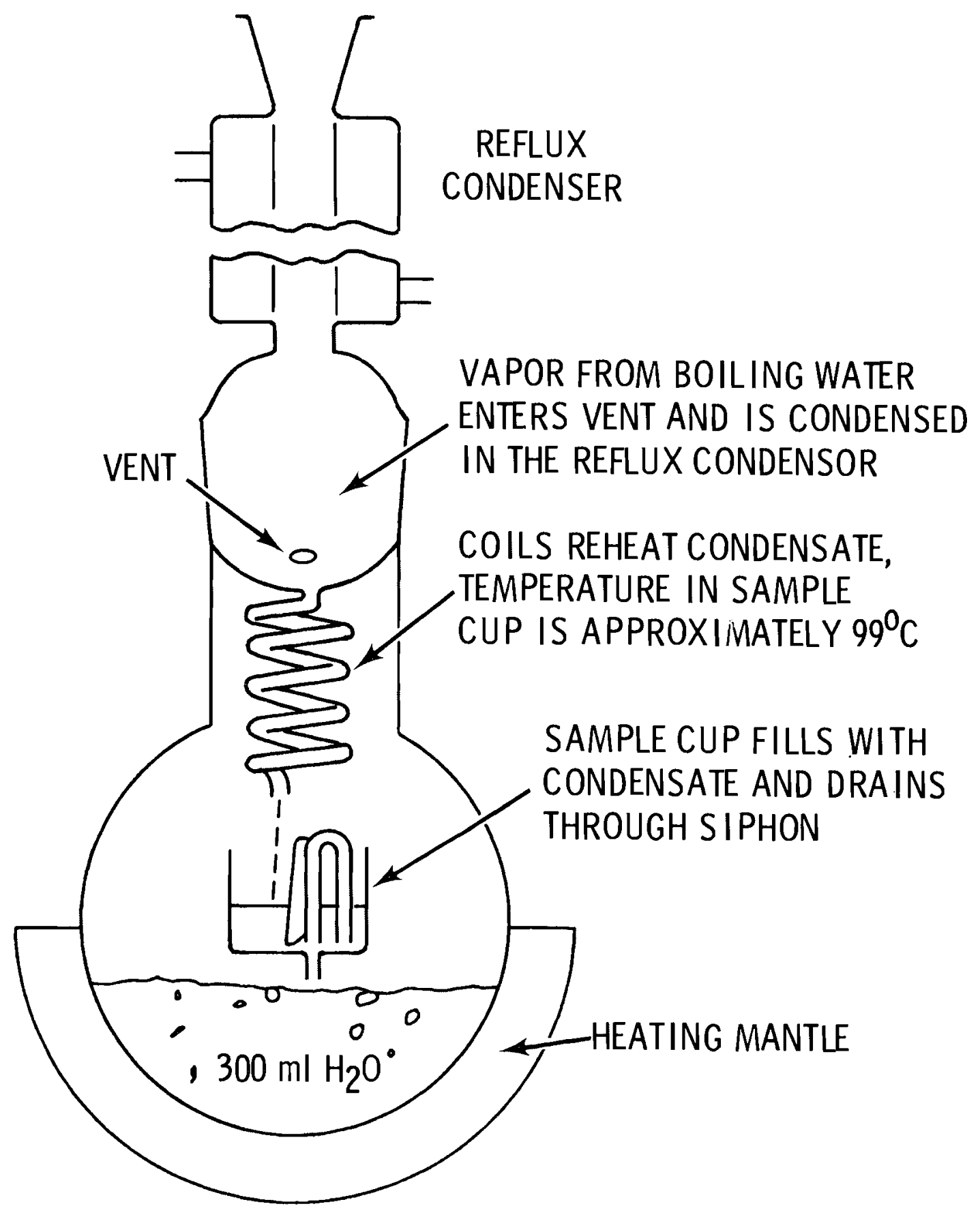

FIGURE 13. Soxhlet Leach Test Apparatus 
or two time periods were used in this study, conclusions cannot be made concerning leaching mechanism or region.

The results of the durability tests are presented in Tables 7 and 8 . These results are expressed both as a percent weight loss and as weight loss per $\mathrm{cm}^{2}$ per dav $\left(\mathrm{g} / \mathrm{cm}^{2}-\mathrm{d}\right)$. The latter is useful to predict penetration into the alass surface if one is in the bulk leaching region. For example. $10^{-5} \mathrm{~g} / \mathrm{cm}^{2}-d$ would correlate to a penetration of $3.9 \times 10^{-6} \mathrm{~cm} /$ day, assuming density of $2.54 \mathrm{~g} / \mathrm{cm}^{3}$ under a bulk leaching mechanism.

In general, the aluminosilicate glasses were much better in Soxhlet and pH 9 environments than the soda-lime-silicates. All glasses were equal in pH 4 buffer solutions. It appears that the twin-ground plate glass may have better leach resistance than the float glasses. This may be due to slight compositional differences as well as surface condition.

SEM micrographs were obtained on the low iron float plate samples 5 and 6 for "as-received" reference (both sides), Soxhlet (both sides), pH 4 (both sides), and $\mathrm{pH} 9$ (both sides), as illustrated in Figures 14-16. No surface effects could be observed on the "as-received" $\mathrm{pH} 4$ and $\mathrm{pH} 9$ samples. Ridges or surface intersections were observed on the Sn side of the Soxhlet sample. The atmosphere side of the Soxhlet sample contained numerous "bumps" or particles which appeared to be from the bulk of the glass (i.e., not a leach product). The Sn side was identified by UV fluorescence and energy dispersive $X$-ray analysis as shown in Figure 17 .

SEM micrographs of representative areas of crushed Soxhlet particies of the low iron float glass sample 6 are shown in Figure 18. Some regions had a "sponge" surface texture whereas others had a smooth surface. The "sponge" texture was not observed on crushed Soxhlet leached samples of aluminosilicate glass. The high weight loss of the crushed float glass samples correlates with the observation of a "sponge-like", probably high silica, gel surface layer. 
TABLE 7. Leachability of Ground Glass Samples $(A)$

\begin{tabular}{|c|c|c|c|c|c|c|c|c|c|c|}
\hline \multirow{3}{*}{ SAMPLE } & \multirow{2}{*}{\multicolumn{2}{|c|}{$\begin{array}{l}\text { SOXHLET } \\
72 \mathrm{HR} \\
\end{array}$}} & \multicolumn{4}{|c|}{$\mathrm{pHO}$} & \multicolumn{4}{|c|}{$\mathrm{pH} 4$} \\
\hline & & & \multicolumn{2}{|c|}{$24 \mathrm{HR}$} & \multicolumn{2}{|c|}{$120 \mathrm{HR}^{(\mathrm{B})}$} & \multicolumn{2}{|c|}{$24 \mathrm{HR}$} & \multicolumn{2}{|c|}{$120 \mathrm{HR}$} \\
\hline & WT\% & $G / C M^{2}-D$ & WT\% & $G / C M^{2}-D$ & WT\% & $G / C M^{2}-D$ & WT\% & $G / C M^{2}-D$ & WT\% & $G / C M^{2}-D$ \\
\hline 1 FLOAT & $23.77 \%$ & 4. $0 \times 10^{-4}$ & $0.15 \%$ & $7.5 \times 10^{-6}$ & $0.18 \%(\mathrm{D})$ & $1.8 \times 10^{-6}$ & $0.05 \%$ & $2.5 \times 10^{-6}$ & $0.05 \%$ & $5.0 \times 10^{-7}$ \\
\hline 6 FLOAT-LOW IRON & 22.53 & $3.8 \times 10^{-4}$ & $0 . \overline{31}$ & $1.6 \times 10^{-5}$ & 0.41 & 4. $1 \times 10^{-6}$ & 0.04 & $2.0 \times 10^{-6}$ & 0.04 & 4. $0 \times 10^{-7}$ \\
\hline 4 FLOAT & 28.35 & 4. $7 \times 10^{-4}$ & 0.15 & $7.5 \times 10^{-6}$ & 0.25 & 2. $5 \times 10^{-6}$ & 0.02 & $1.0 \times 10^{-6}$ & $0.34^{(D)}$ & $3.4 \times 10^{-6}$ \\
\hline 12 TWIN GROUND & 9.64 & $1.6 \times 10^{-4}$ & 0.08 & $4.0 \times 10^{-6}$ & 0.21 & $2.1 \times 10^{-6}$ & 0.10 & 5. $0 \times 10^{-6}$ & 0.10 & $1.0 \times 10^{-6}$ \\
\hline 7 FUSION & 1.08 & $1.8 \times 10^{-5}$ & 0.02 & $1.0 \times 10^{-6}$ & 0.04 & 4. $0 \times 10^{-7}$ & 0.06 & 3. $0 \times 10^{-6}$ & 0.06 & $6.0 \times 10^{-7}$ \\
\hline 13 & 1.78 & 3. $0 \times 10^{-5}$ & $0^{(\mathrm{C})}$ & 0 & 0.03 & $3.0 \times 10^{-7}$ & 0.05 & $2.5 \times 10^{-6}$ & 0.05 & $5.0 \times 10^{-7}$ \\
\hline
\end{tabular}
(A) SCREENED TO $-40+60 \mathrm{MESH}$, SURFACE AREA ASSUMED AS $200 \mathrm{~cm}^{2} / \mathrm{g}$
(B) AN ADDITIONAL 96 HRS AFTER FIRST 24 HR TEST
(C) NO MEASURABLE WEIGHT LOSS DURING TESTING PERIOD
(D) POSSIBLE EXPERIMENT ERROR 
TABLE 8. Leachability of Plate Glass Samples (A)

\begin{tabular}{|c|c|c|c|c|c|c|c|c|}
\hline \multirow{3}{*}{ SAMPLE } & \multirow{2}{*}{\multicolumn{2}{|c|}{$\begin{array}{c}\text { SOXHLET } \\
72 \mathrm{HR}\end{array}$}} & \multicolumn{4}{|c|}{$\mathrm{pH} 9$} & \multirow{2}{*}{\multicolumn{2}{|c|}{$\begin{array}{c}\mathrm{pH} 4 \\
24 \mathrm{HR}\end{array}$}} \\
\hline & & & \multicolumn{2}{|c|}{$24 \mathrm{HR}$} & \multicolumn{2}{|c|}{$168 \mathrm{HR}$} & & \\
\hline & WT\% & $G / C M^{2}-D$ & WT\% & $G / C M^{2}-D$ & WT\% & $G / C M^{2}-D$ & WT\% & $G / C M^{2}-D$ \\
\hline 1 FLOAT & $0.86 \%$ & $7.6 \times 10^{-4}$ & $0.05 \%$ & $1.3 \times 10^{-4}$ & $0.04 \%$ & $2.9 \times 10^{-5}$ & $0.01 \%$ & $2.5 \times 10^{-5}$ \\
\hline 2 FLOAT & $N D^{(c)}$ & ND & ND & ND & 0.03 & 2. $1 \times 10^{-5}$ & ND & ND \\
\hline 6 FLOAT-LOW IRON & 0.91 & $8.3 \times 10^{-4}$ & 0.2 & $5.6 \times 10^{-5}$ & 0.02 & $1.4 \times 10^{-5}$ & 0 & 0 \\
\hline 5 FLOAT & ND & ND & ND & ND & 0.05 & $3.6 \times 10^{-5}$ & ND & ND \\
\hline 4 FLOAT & 1.11 & $1.0 \times 10^{-3}$ & 0.02 & $5.7 \times 10^{-5}$ & 0.02 & $1.4 \times 10^{-5}$ & 0 & 0 \\
\hline 12 TWIN GROUND & 0.29 & 3. $9 \times 10^{-4}$ & $0^{(B)}$ & 0 & 0.04 & 2. $9 \times 10^{-5}$ & 0.01 & $3.7 \times 10^{-5}$ \\
\hline 7 FUSION & 0.04 & $3.2 \times 10^{-5}$ & 0 & 0 & 0.05 & $3.6 \times 10^{-5}$ & 0.03 & $7.6 \times 10^{-5}$ \\
\hline
\end{tabular}
(A) SURFACE AREA RANGED FROM $2-4 \mathrm{~cm}^{2} / \mathrm{g}$
(B) NO MEASURABLE WEIGHT LOSS DURING TESTING PERIOD
(C) ND - NOT DETERMINED 


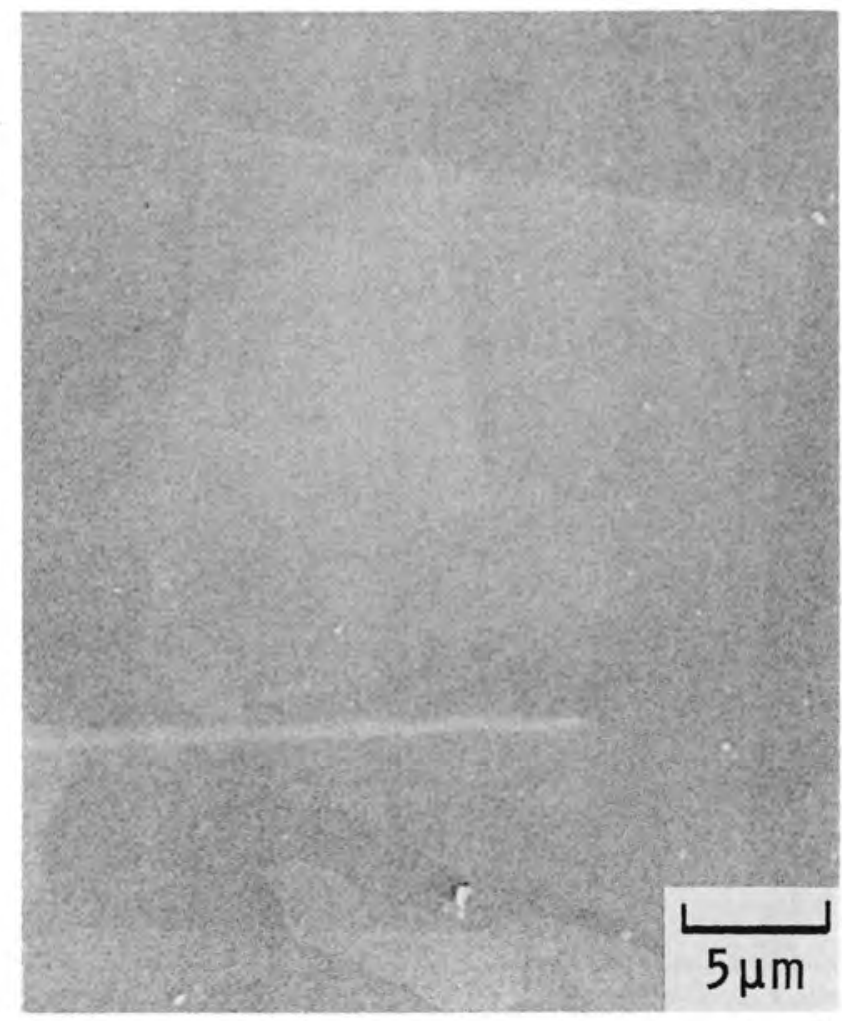

BATH SIDE

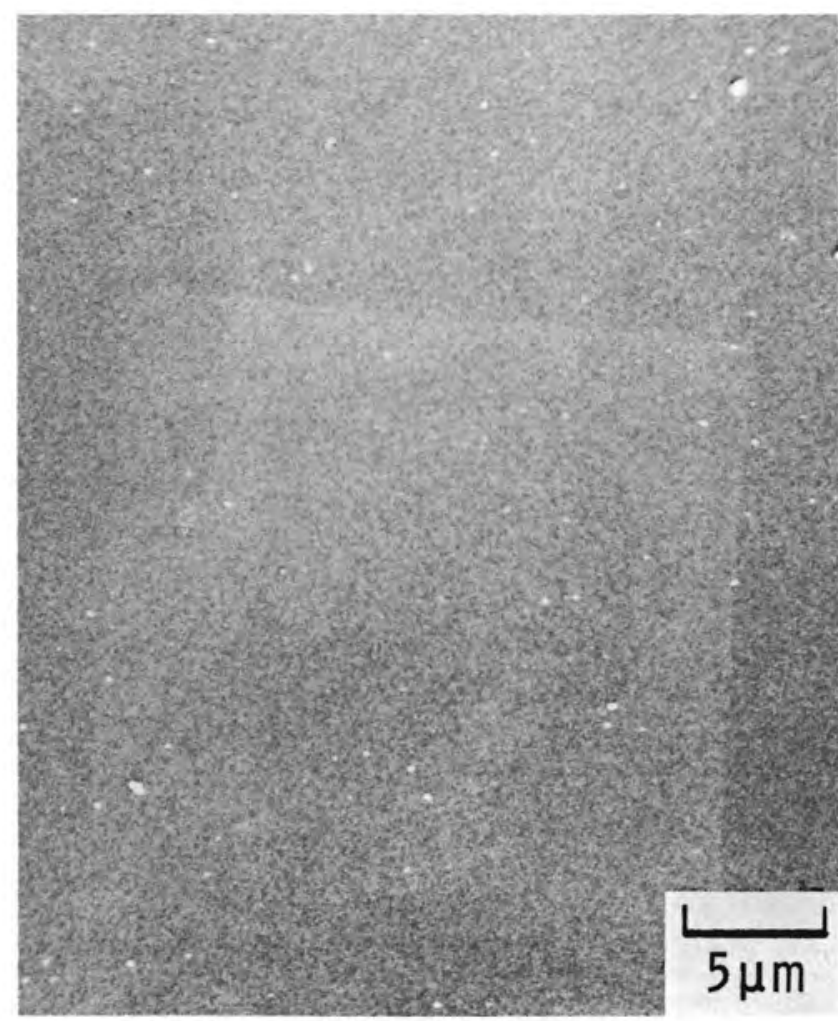

ATMOSPHERE SIDE

FIGURE 14. SEM Micrographs of Reference PPG Low Iron Plate Glass 


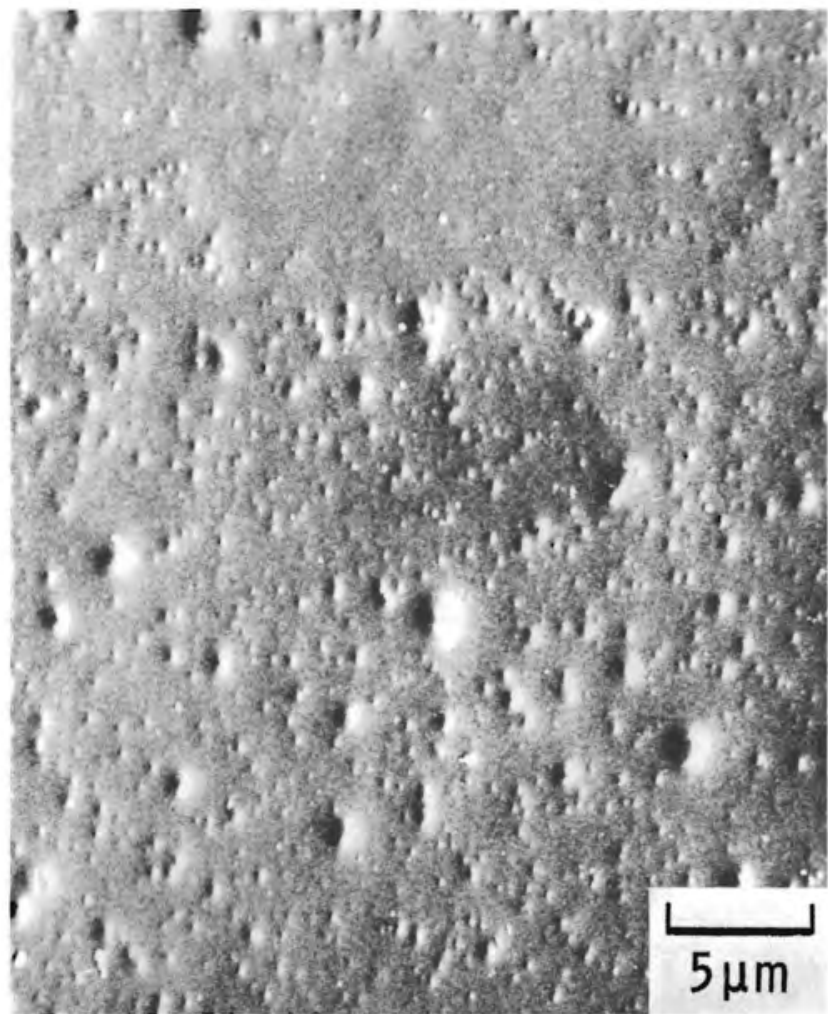

BATH SIDE $45^{\circ}$ TILT ANGLE

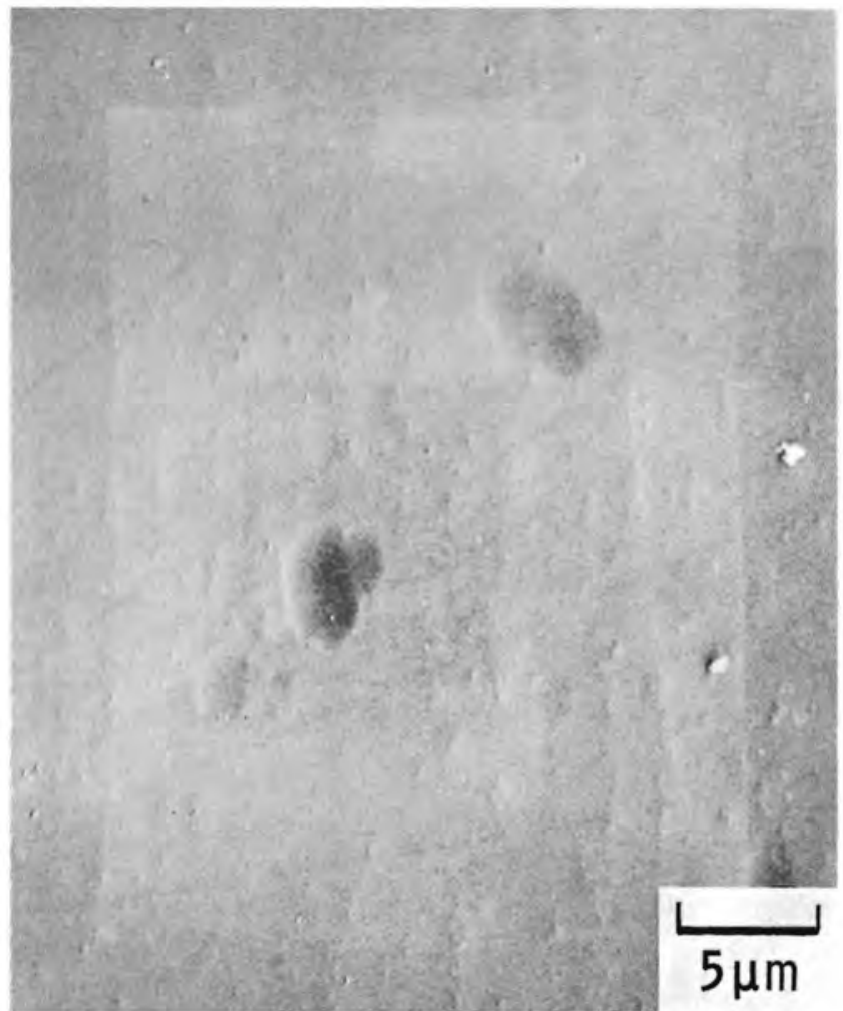

ATMOSPHERE SIDE $45^{\circ}$ TILT ANGLE

FIGURE 15. SEM Micrographs of PPG Low Iron Plate Glass Soxhlet Leached for $72 \mathrm{Hr}$ 


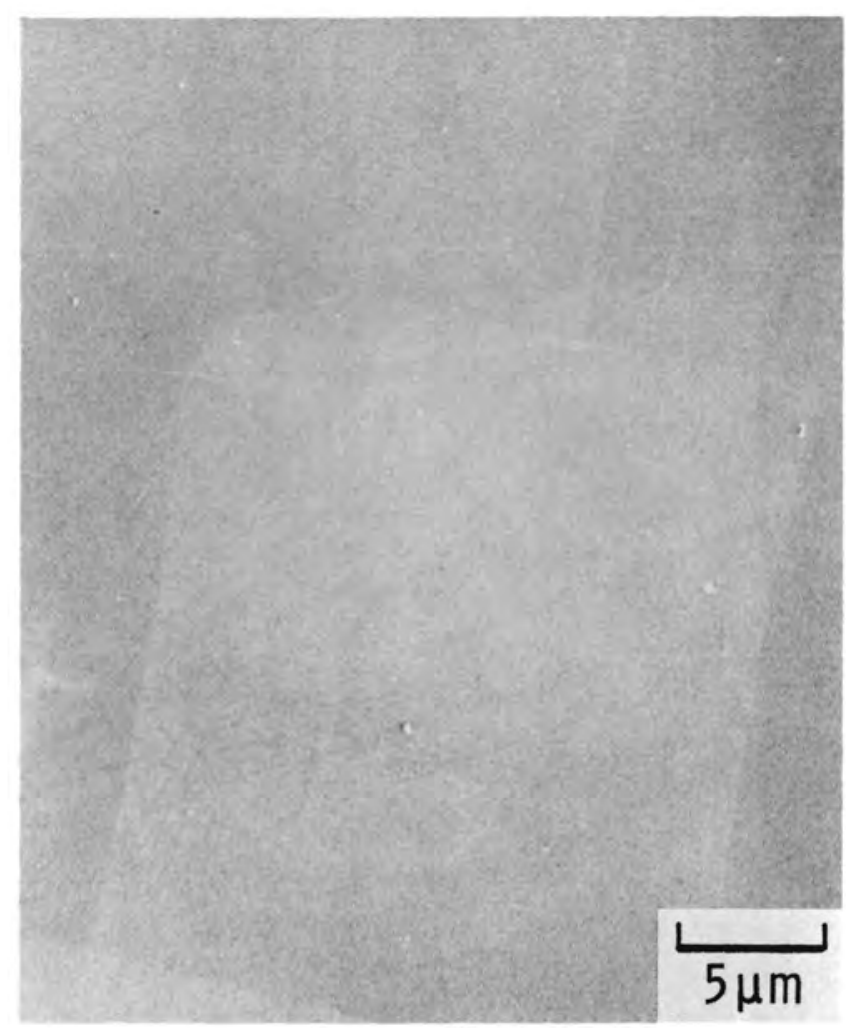

pH 4 - 24 HR

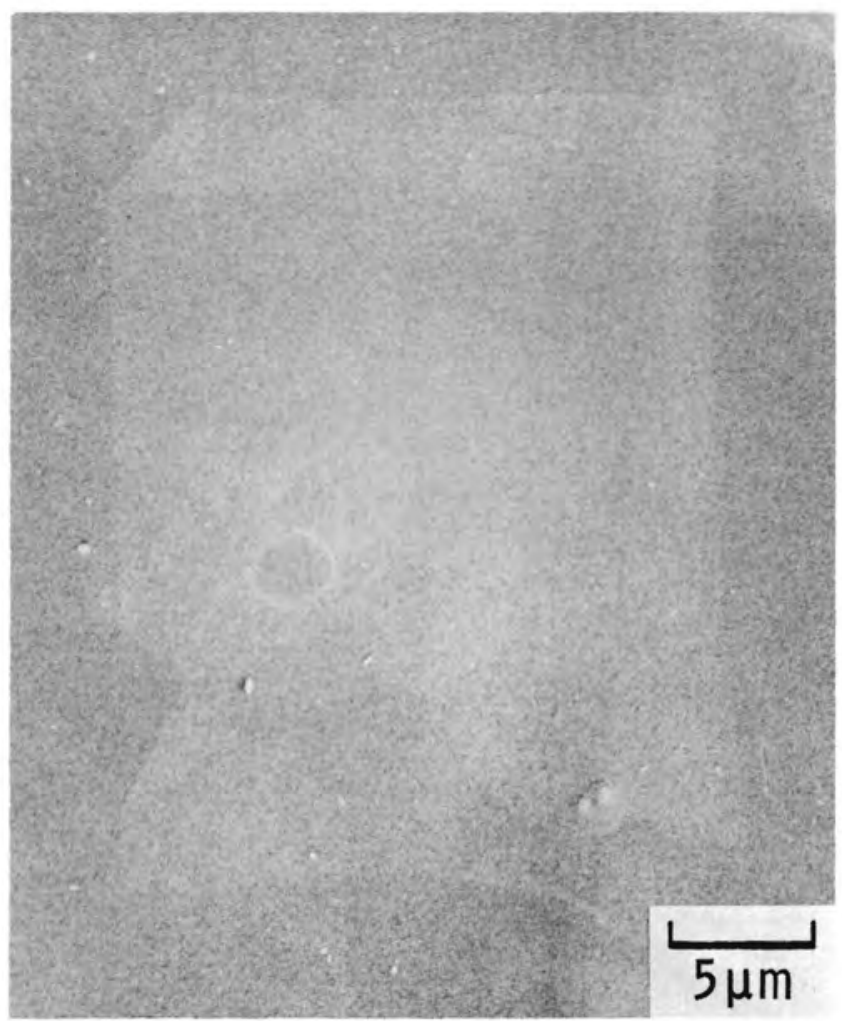

pH $9-24$ HR

FIGURE 16. SEM Micrographs of PPG Low Iron Plate Glass $\mathrm{pH} 4$ and pH 9 Leached 


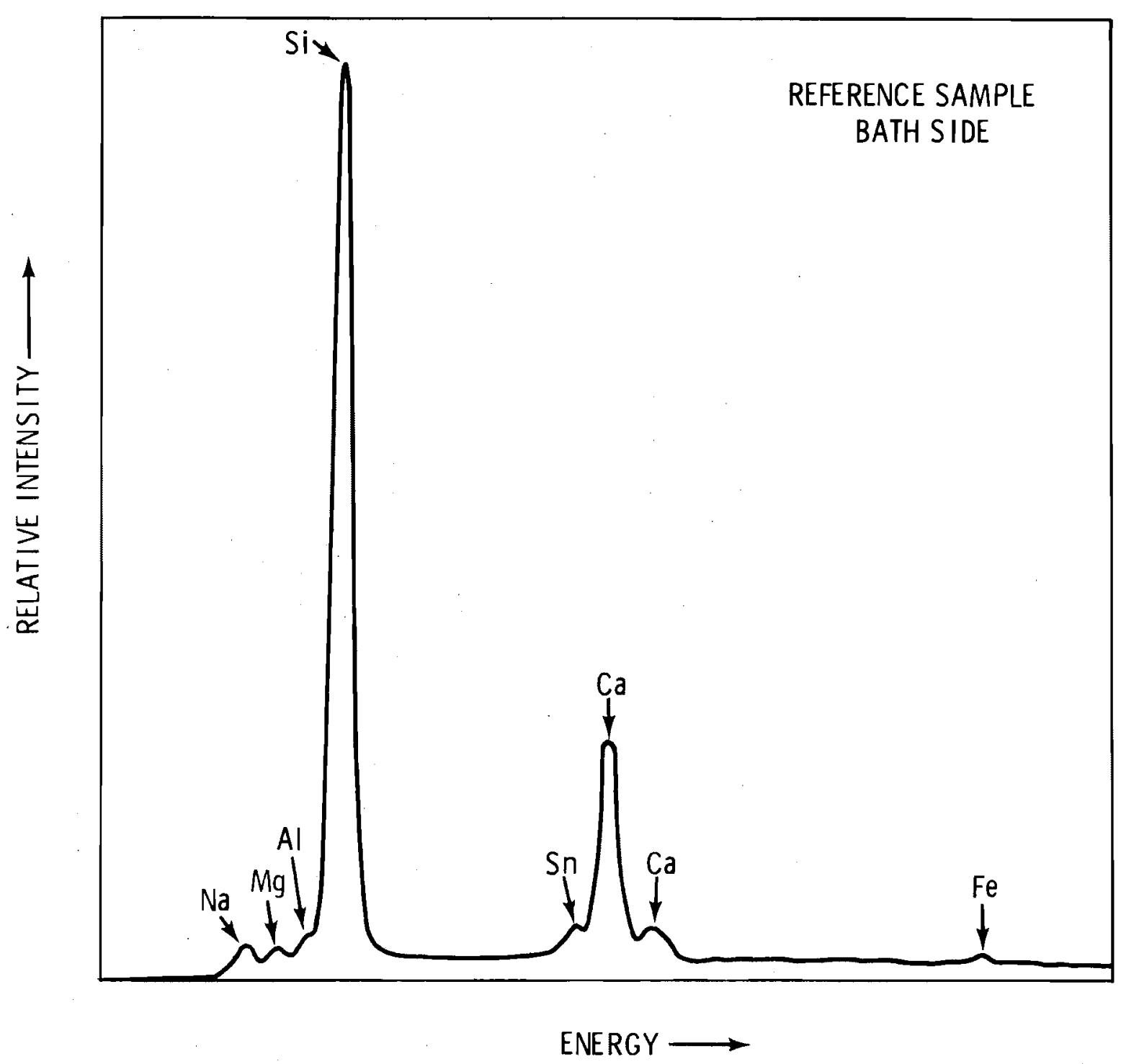

FIGURE 17. Energy Dispersive X-Ray Fluorescence Analysis of Low Iron Plate Glass Sample 6 

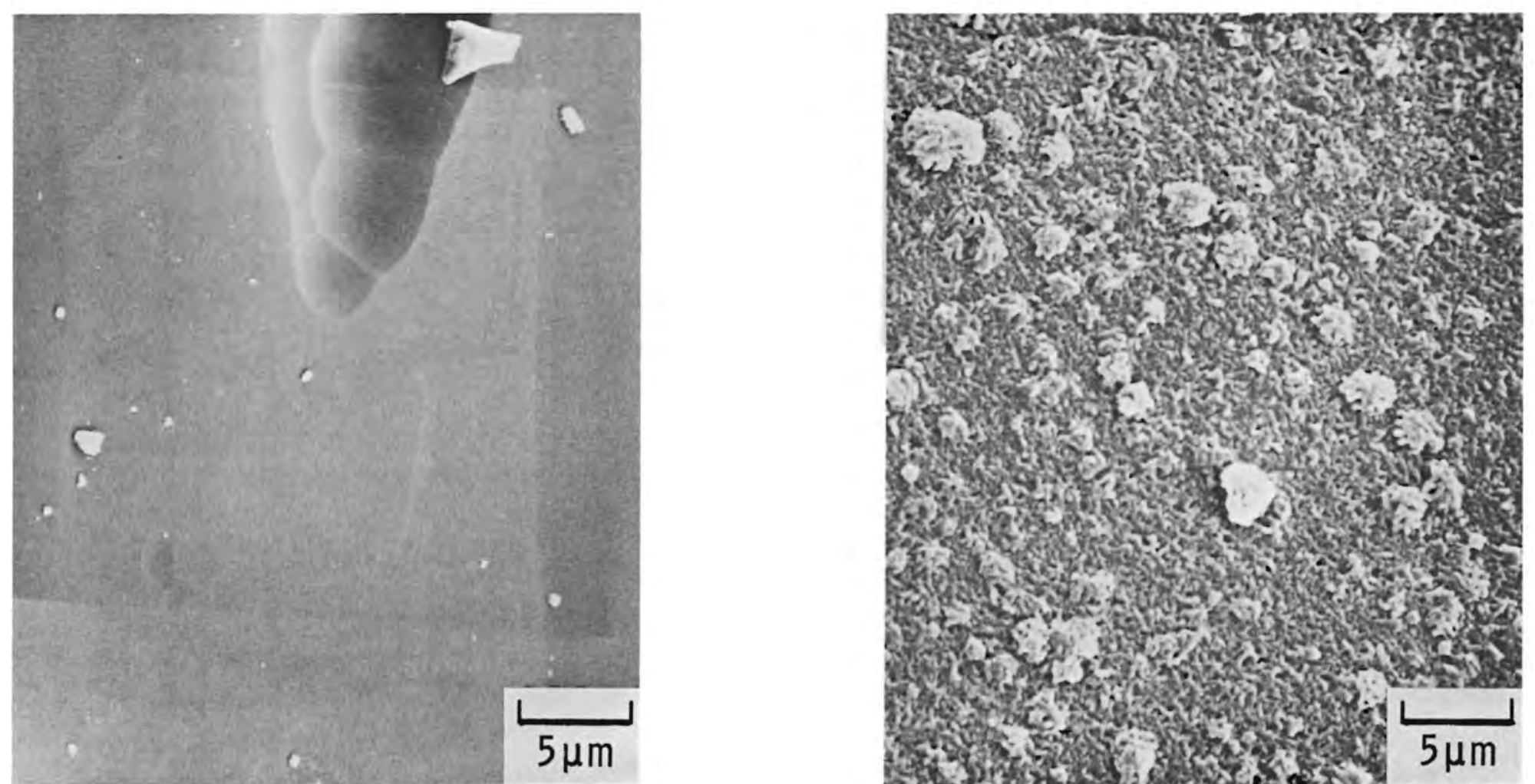

FIGURE 18. SEM Micrographs of Powdered PPG Low Iron Glass Soxhlet Leached for $72 \mathrm{Hr}$ 
Since similar behavior was not observed between the plate and crushed samples, it is suggested that experimental parameters such as surface area to volume affect the results. Hench has observed that leaching characteristics of glass are dependent upon the ratio of sample surface area to solution volume. $(4,5)$ As mentioned above and illustrated in Figure 18, leached surfaces of ground glass particles differ from particle to particle. Thus, it also appears that the leaching behavior of crushed particles is not consistent between similar particles. Thus, it is recommended that plate samples be used in measurements to determine the durability of proposed glass for hel iostat mirrors.

SEM micrographs were obtained for the "as-received" reference and Soxhlet twin ground plate sample 12 as shown in Figure 19. The Soxhlet sample contained a few surface "holes" and some raised portions. The surface was not as greatly affected as the float sample 6 . The surface texture became much more distinct by observation of the sample at a $45^{\circ}$ tilt angle instead of $0^{\circ}$. This effect is demonstrated in Figure 20. The composition of the twin ground plate is similar to that of float glass as illustrated in Figure 21.

The aluminosilicate fusion glass sample 7 demonstrated no surface attack by Soxhlet leaching under SEM analysis as evidenced by the comparison of the SEM micrographs in Figure 22. As previously discussed, crushed particles of the aluminosilicate glass which had undergone Soxhlet leaching contained some surface particulate but did not contain any sponge-like texture or silica-gel layer. The composition of aluminosilicate fusion glass differs from sodaline-silica float glass in that $\mathrm{K}$ and $\mathrm{Ba}$ are present; $\mathrm{Ca}$ is reduced and $\mathrm{Al}$ increased as illustrated in Figure 23.

In summary, the results from the Soxhlet, $\mathrm{pH} 4$ and $\mathrm{pH} 9$ leach tests indicate that an aluminosilicate glass has better leach resistance than sodalime-silicates under Soxhlet and $\mathrm{pH} 9$ environments. These results correlate with previous work of P. B. Adams ${ }^{(6)}$, illustrated in Figure 24 . It is difficult, if not impossible, to predict what this implies about the desired durability of heliostat mirrors at Barstow, California. The room temperature 


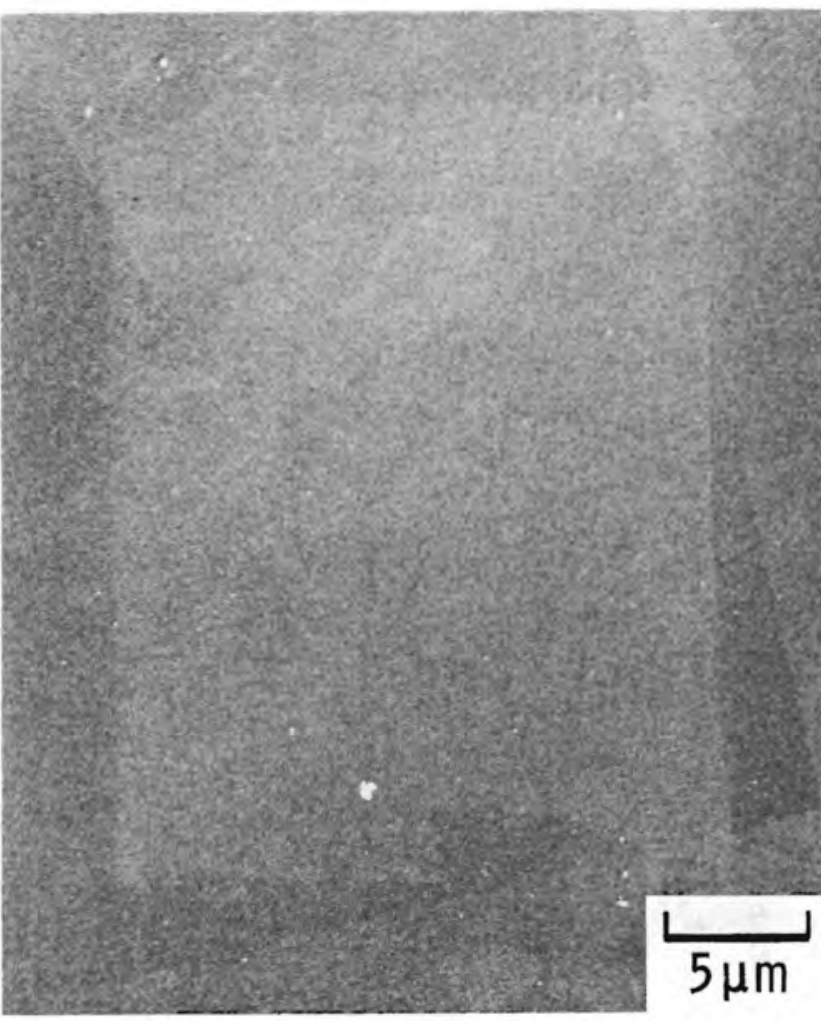

REFERENCE

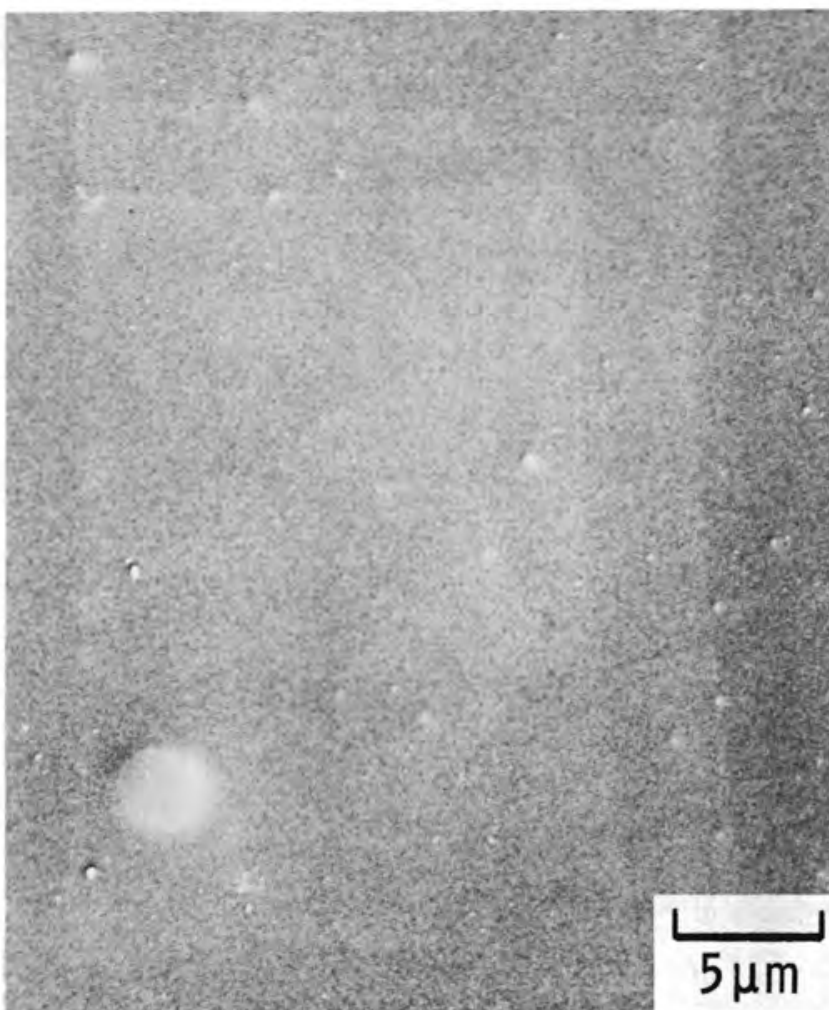

SOXHLET - 72 HR

FIGURE 19. SEM Micrographs of ASG Twin Ground Plate Glass Reference and Soxhlet Leached 


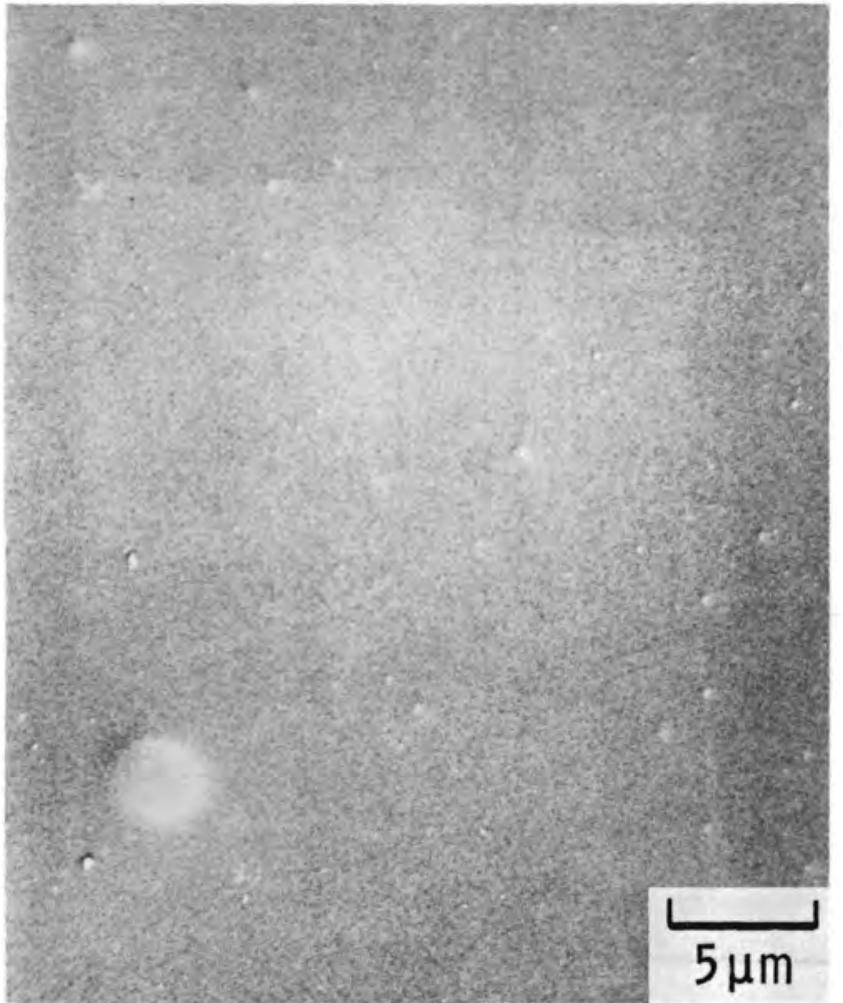

$0^{0}$ TILT ANGLE

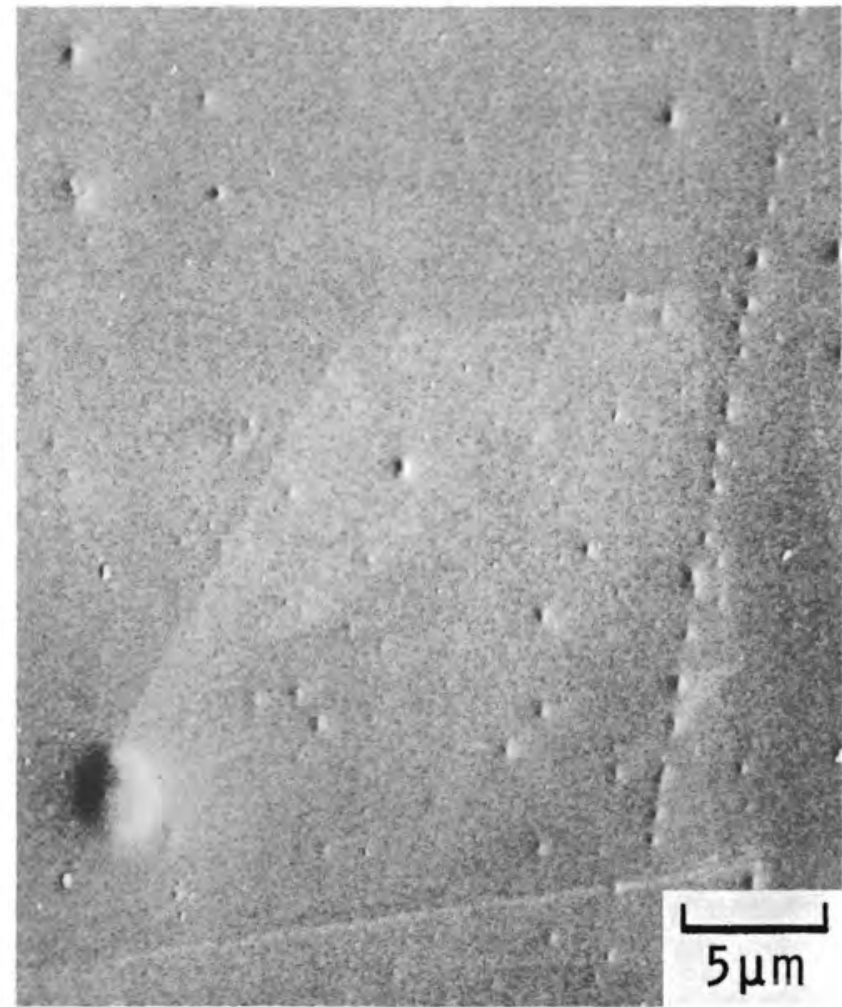

$45^{\circ}$ TILT ANGLE

FIGURE 20. SEM Micrographs of ASG Twin Ground Plate Glass Soxhlet Leached for $72 \mathrm{Hr}$ 


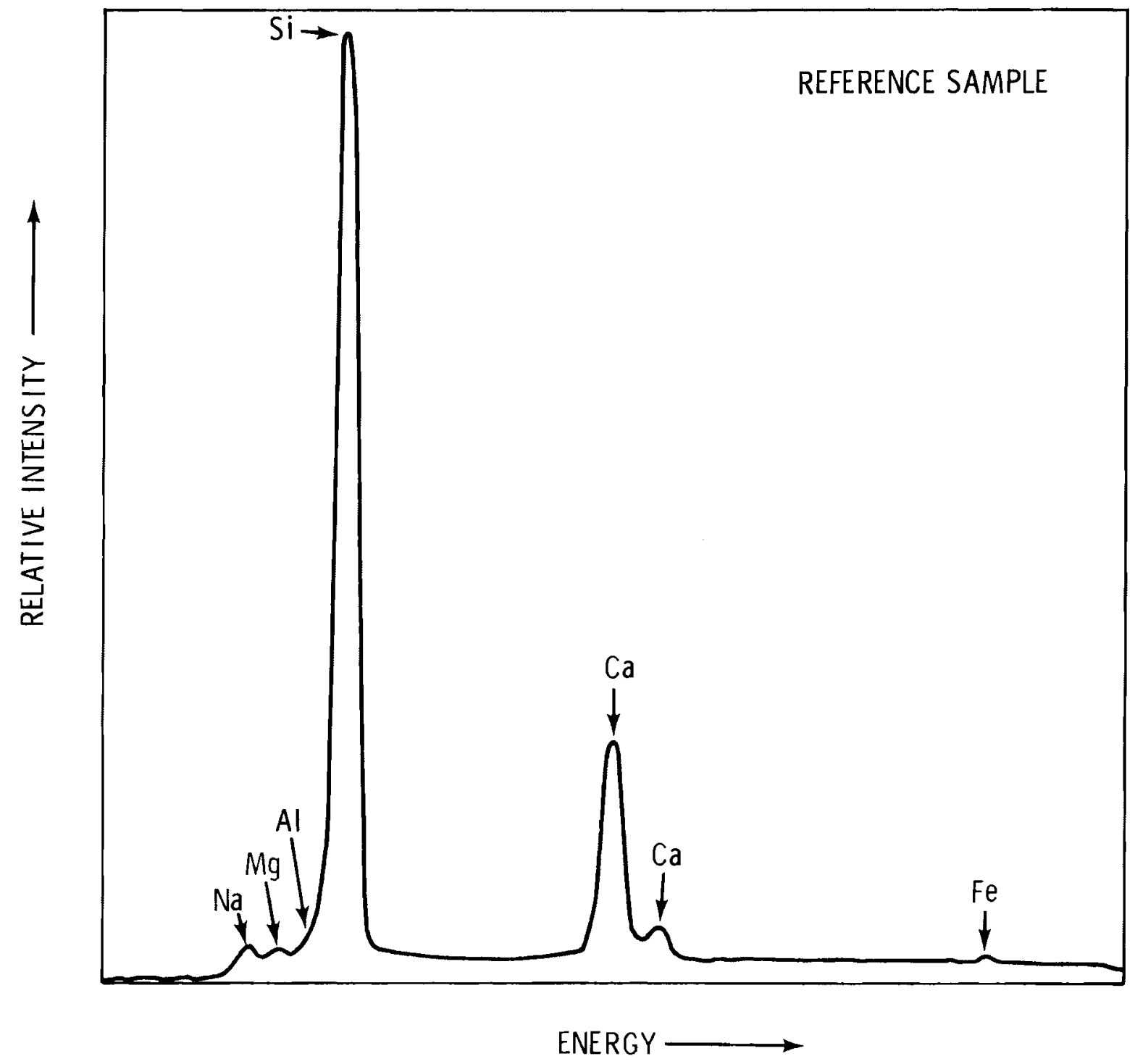

FIGURE 21. Energy Dispersive X-Ray Fluorescence Analysis of Twin Ground Plate Glass Sample 12 


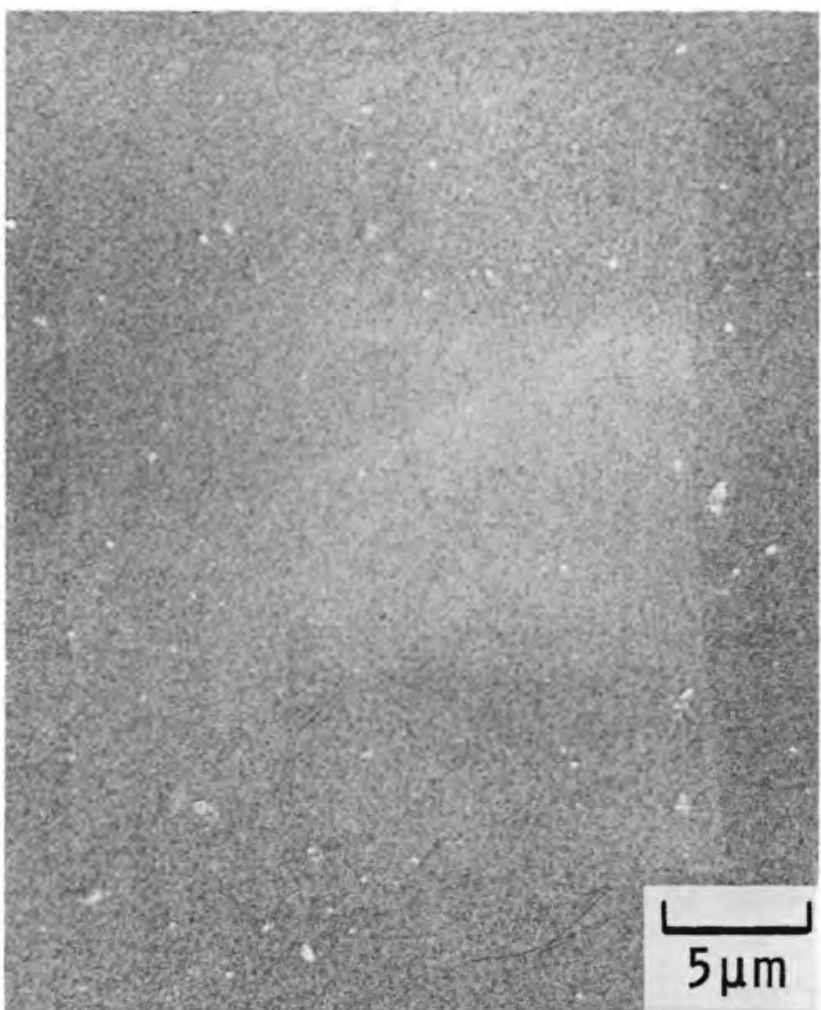

REFERENCE

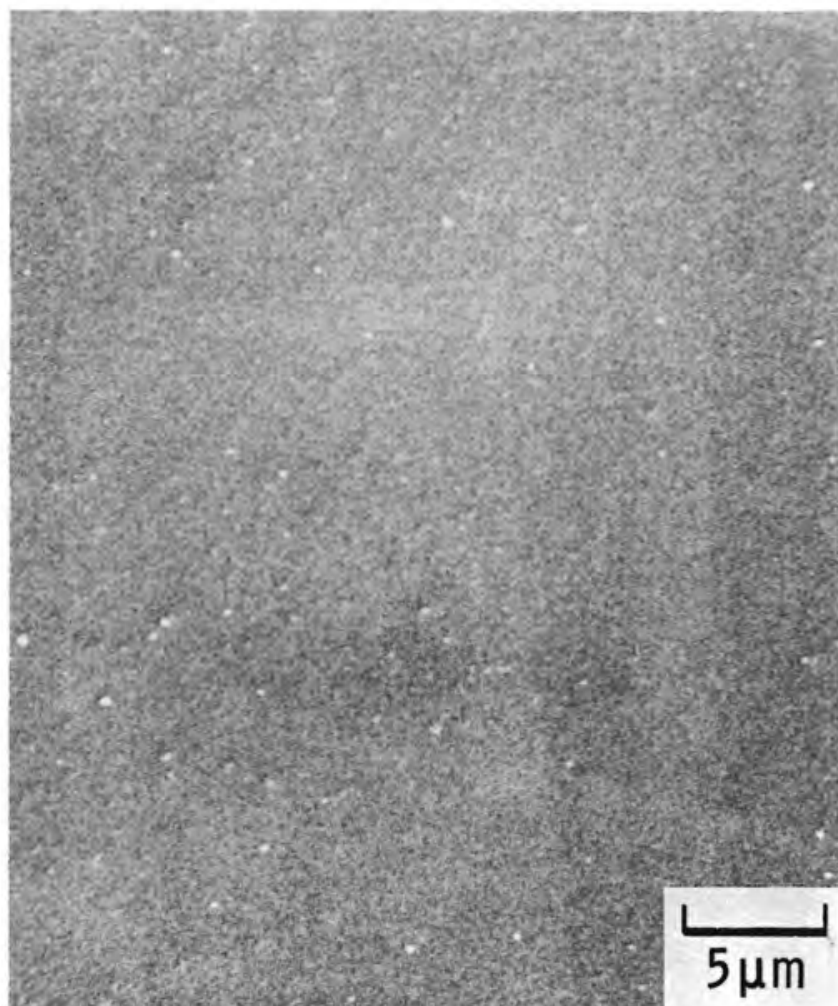

SOXHLET-72HR

FIGURE 22. SEM Micrographs of CGW Fusion 0317 Plate Glass Reference and Soxhlet Leached 


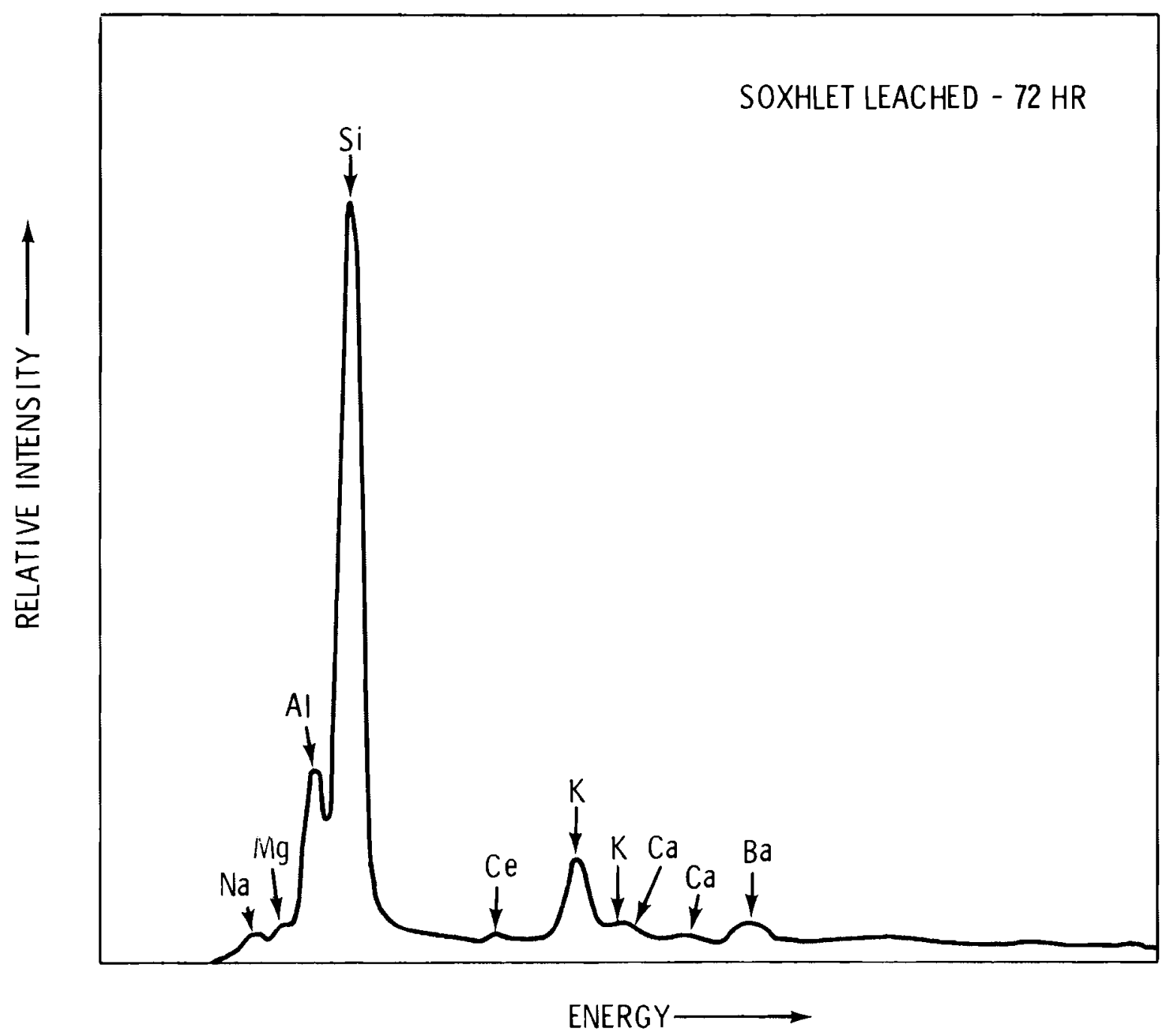

FIGURE 23. Energy Dispersive X-Ray Fluorescence Analysis of Fusion Plate Glass Sample 7 


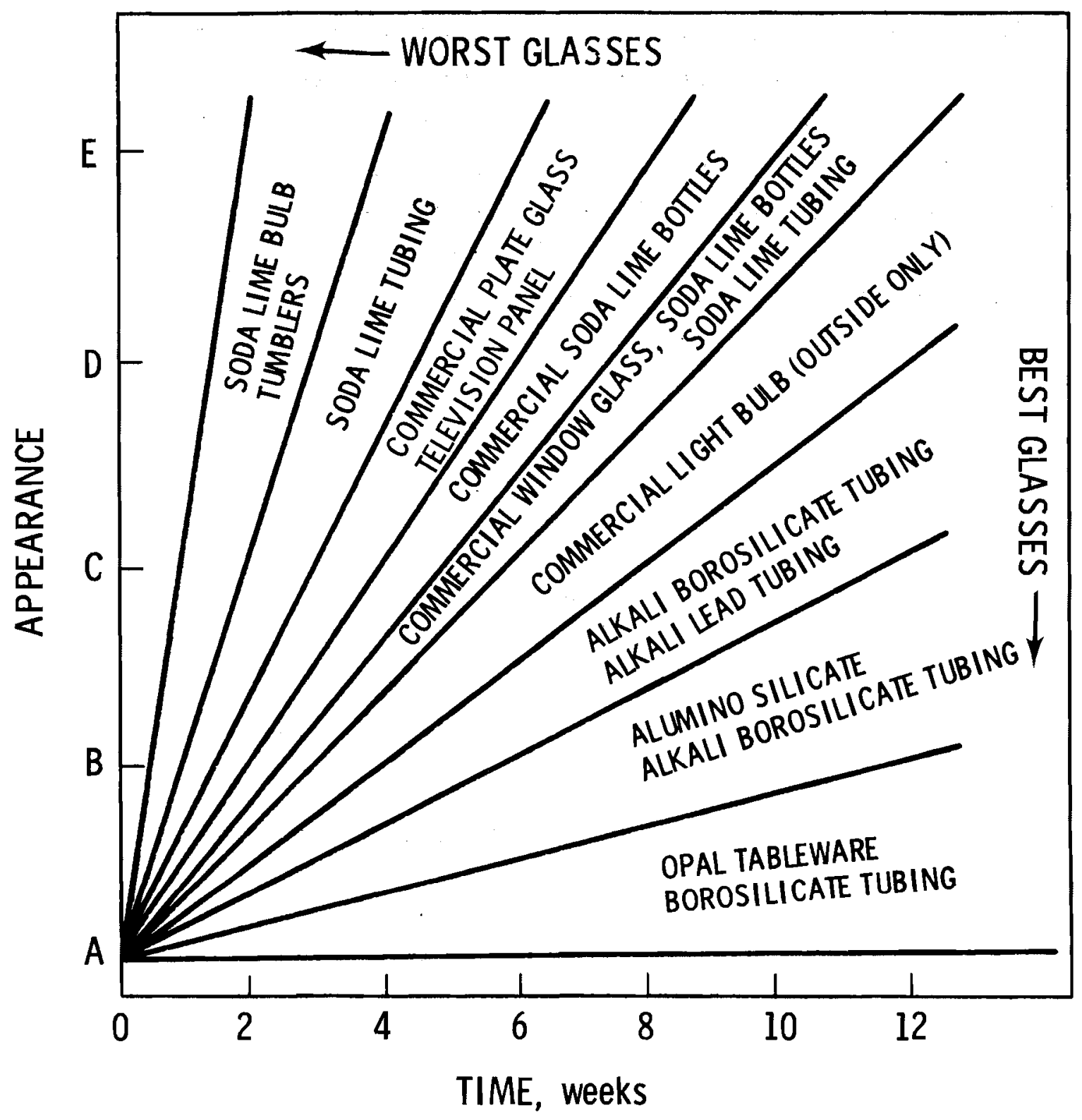

FIGURE 24. Glass Durability Comparison 
leachability expressed as percent weight loss in acid and base conditions of all plate samples tested was between 0.01 and $0.05 \mathrm{wt} . \%$, which is probably acceptable for hel iostat mirrors.

Further studies need to be conducted to determine the kinetics of surface defects due to leaching and their effects on glass/mirror properties. Penetration or alteration layer depth should be determined versus temperature and time under leach conditions similar to the test site environment. Weight loss measurements are sufficient for scoping tests but kinetics are necessary to correlate and predict behavior in the actual environment. Specularity and transmission measurements must also be made on the leached samples to determine the effect of the leached surface on heliostat performance. 


\section{OTHER PROPERTIES OF COMMON GLASSES}

The mean coefficient of 1 inear thermal expansion was determined from 25 to $300^{\circ} \mathrm{C}$ for selected glasses using the ASTM dilatometric method. (7) The results are 1isted in Table 9. Representative properties of generic glasses are listed in Table 10. For comparison, the coefficients of linear thermal expansion are included in Table 9.

TABLE 9. Linear Thermal Expansion of Selected Glasses

$$
\text { Coefficient of Linear Expansion }
$$

Measured Value(a) Commercial Value(b)

Glass

$\times 10^{-7} /{ }^{\circ} \mathrm{C}$

$\times 10^{-7} /{ }^{\circ} \mathrm{C}$

Soda-lime-silica

Sample 6

83.6

93.5

Aluminosilicate

85.0

88.0

Sample 7

Lime-borosilicate

Sample 14

68.1

69.0

\footnotetext{
(a) Measured from $25^{\circ} \mathrm{C}$ to $300^{\circ} \mathrm{C}$

(b) From Table 10
} 
TABLE 10. Physical Properties of Several Types of Glasses

\begin{tabular}{|c|c|c|c|c|}
\hline & $\begin{array}{l}\text { Soda Lime } \\
\text { Silica } \\
\end{array}$ & $\begin{array}{l}\text { Alumino- } \\
\text { silicate }\end{array}$ & $\begin{array}{c}\text { Lime } \\
\text { Borosilicate }\end{array}$ & $\begin{array}{c}\text { "Pyrex" } \\
\text { Borosilicate }\end{array}$ \\
\hline $\begin{array}{l}\text { Coefficient of Thermal } \\
\text { Expansion }\left(\times 10^{-7} /{ }^{\circ} \mathrm{C}\right)\end{array}$ & 93.5 & 88 & 69 & 32 \\
\hline \multicolumn{5}{|l|}{ Weatherability $(20 \mathrm{yr})$} \\
\hline $\begin{array}{l}1 \text { None } \\
2 \text { Slight } \\
3 \text { Moderate-Severe } \\
\text { Visual Degradation }\end{array}$ & 3 & 1 & 1 & 1 \\
\hline $\begin{array}{l}\text { Liquid Viscosity } \\
{ }^{\circ} \mathrm{C} \text { Working Pt }\end{array}$ & 1013 & $\mathrm{NA}^{\dagger}$ & 1091 & 1245 \\
\hline Softening $\mathrm{Pt}{ }^{\circ} \mathrm{C}$ & 696 & NA & 755 & 820 \\
\hline Annealing $\mathrm{Pt}{ }^{\circ} \mathrm{C}$ & 514 & NA & 750 & 565 \\
\hline Strain $\mathrm{Pt}{ }^{\circ} \mathrm{C}$ & 473 & NA & 535 & 515 \\
\hline Density $\mathrm{g} / \mathrm{cm}^{3}$ & 2.47 & NA & 2.43 & 2.23 \\
\hline Cost & $2.5 \$ / 1 b$ & NA & $5 \notin / 1 b$ & NA \\
\hline
\end{tabular}

+ Not available 


\section{SUMMARY OF GLASS MANUFACTURER SURVEY}

The survey identified four basic methods of producing large quantities of flat glass. These methods are identified as float, fusion, rolled and twin ground. In the float process, the convectively mixed molten glass flows into a bed of molten tin and is mechanically pulled and stretched to its desired thickness. In the fusion process, the molten glass is allowed to overflow a trough-like container and is drawn down by gravity or mechanically pulled to its desired thickness. In the rolled process, the molten glass flows between a series of rollers and is extruded to its desired thickness. Twin ground glass is produced by any of the above processes and then ground and polished on both surfaces to yield a very flat product. Each of these processes has its own advantages and disadvantages for producing glass for heliostat applications.

Only the rolled glass appears to be unsuitable for heliostat construction in its present state of development because of its inherent surface waviness. It does have one advantage, however; it can be produced with relatively low iron content $(0.01 \%)$. This corresponds to a solar transmittance of 0.91 or greater for $0.125 \mathrm{in}$. thick glass. Most rolled glasses produced today are patterned.

One possibility for overcoming the flatness problem is to twin grind the rolled glass. Although no high transmission samples of twin ground glass have been evaluated, it has been demonstrated that the grinding process is capable of producing the flattest glass in the industry. There is a lower limit of about $4 \mathrm{~mm}$ on the thickness, but the thinner glass can be made at the cost of increased breakage. The survey identified only one plant (Franklin Glass Works) that is currently producing ground glass. There are several other plants in existence (ASG) which are presently mothballed due to EPA regulations on effluent, but could be reopened if sufficient incentive existed.

The float process is a high volume process. Most lines produce $0.125 \mathrm{in}$. glass in excess of 100 million square feet per year. The process is highly 
dependent on convective mixing in the melting tank. The emissivity of the molten glass plays an important role in the critical temperature profile which promotes mixing within the tank. The clear glass must be processed at higher temperatures or in deeper tanks to insure proper mixing. Most of the glass industry thinks that float glass with $0.05 \%$ iron corresponding to a solar transmittance of over 0.89 can be produced without a drastic modification of present facilities.

The main obstacle in obtaining very low iron float is developing sufficient market incentive for the manufacturers to produce it. At the present time, all the float lines in the country are producing to capacity and the solar market has not yet reached the magnitude where it could support even one line. The changeover process from producing the higher iron content glasses to producing the lower iron content glasses could take as long as a month to accomplish. Thus, reducing the iron content of the glass line would result in a large volume of intermediate iron content glass for which there is no apparent market.

The highest transmission glass that has been produced on a float line is an experimental run of 0.125 in. glass (Sample 6 ). The solar transmittance of the glass is greater than 0.88 , but the quality is not as high as could be expected in future runs. The manufacturers of float glass see no obstacles to producing glass as thin as $0.070 \mathrm{in.}-0.080 \mathrm{in.}$, although the optical quality may be more of a problem at these thicknesses.

At the present time the fusion glass process may be the only practical alternative to the float process. The aluminosilicate glass has a high solar transmittance ( $>0.90$ for $0.10 \mathrm{in.})$, and it can be produced in thicknesses ranging from $0.020 \mathrm{in}$. to $0.480 \mathrm{in}$. The aluminosilicate formulation has a relatively high manufacturing cost, and therefore the manufacturer recommends an alternate formulation which has a lower manufacturing cost, a lime borosilicate. The lime borosilicate, like the aluminosilicate, is a more durable glass than the soda lime glass produced in the float process. The line capacity of twenty million square feet per year for fusion glass is smaller than float line capacity and therefore is more adaptable to 
change. The lime-borosilicate glass is not currently being produced in sheet form, but it may be a viable option for future runs (especially for thin glass).

A summary comparing the present options for flat glass from the sources surveyed is given in Table 11. It should be noted that the survey was conducted from February to May 1978 and may not represent current data. This is especially true with respect to pricing information. 


\section{TABLE 11. Glass Manufacturer Product Comparison Summary}

\begin{tabular}{|c|c|c|c|c|c|c|c|c|c|c|}
\hline \multirow[b]{2}{*}{ MANUFACTURER } & \multirow[b]{2}{*}{ PROCESS } & \multirow[b]{2}{*}{ COMPOSIIION } & \multicolumn{2}{|c|}{ IHICKNESS } & \multicolumn{2}{|c|}{ SOLAR IRANSMITANCE } & \multicolumn{2}{|c|}{$\begin{array}{l}\text { OPIICAL FLATNESS } \\
\text { \% POWER OUTSIDEE }\end{array}$} & \multicolumn{2}{|c|}{$\begin{array}{c}\text { APPROXIMAIE COSI } \\
\text { PER SQ.F. }\end{array}$} \\
\hline & & & TESTED & POSSIBLE & MEASURED & POSSIBLE & 1 MRAD & $\underline{2 M R A D}$ & IM SQ.F. & $\geq 10 \mathrm{M}$ SQ.F. \\
\hline 4 & $\begin{array}{l}\text { LO-IRON } \\
\text { FLOAT }\end{array}$ & SODA LIME & 0.125 & & 0.847 & & & & $0.30^{(4)}$ & 0.30 \\
\hline 4 & $\begin{array}{l}\text { LO-IRON } \\
\text { TWIN GROUND }\end{array}$ & SODA LIME & & $>4 \mathrm{~mm}$ & & $>0.91$ & $0^{(3)}$ & $0^{(3)}$ & 1.30 & \\
\hline 2 & FLOAT & SODA LIME & 0.125 & & 0.838 & & 18 & 1 & 0.50 & \\
\hline 2 & $\begin{array}{l}\text { LO-IRON } \\
\text { TWIN GROUND }\end{array}$ & SODA LIME & & & & $>0.91$ & $0^{(3)}$ & $0^{(3)}$ & 1.30 & \\
\hline 7 & FUSION & ALUMINOSILICATE & 0.110 & $>0.020$ & 0.903 & & 15 & 0 & $0.65-0.80$ & \\
\hline 8 & FUSION & ALUMINOSILICATE & 0.090 & & 0.910 & & 19 & 0 & $0.65-0.80^{(5)}$ & \\
\hline 9 & FUSION & ALLIMINOSILICATE & 0.060 & & 0.909 & & 46 & 22 & $0.45-0.70$ & \\
\hline 14 & FUSION & $\begin{array}{l}\text { LIME } \\
\text { BOROSILICATE }\end{array}$ & 0.045 & & $0.876^{(2)}$ & $>0.91$ & & & 1.40 & 0.45 \\
\hline 10 & ROLLED & SODA LIME & 0.125 & & 0.891 & & 90 & 57 & & \\
\hline 3 & FLOAT & SODA LIME & 0.125 & $>0.105$ & 0.844 & $>0.88$ & 5 & 0 & $0.40^{(6)}$ & \\
\hline 15 & FLOAT & SODA LIME & & $>0.085$ & & $>0.88$ & & & 1.00 & \\
\hline 1 & FLOAT & SODA LIME & 0.125 & & 0.831 & & 7 & 0 & & \\
\hline 5 & $\begin{array}{l}\text { MID -IRON } \\
\text { FLOAT }\end{array}$ & SODA LIME & 0.125 & & 0.866 & & 8 & 0 & & \\
\hline 6 & LO-IRON & SODA LIME & 0.125 & $>0.060$ & 0.881 & $>0.89$ & 20 & 4 & $2.15^{(7)}$ & $0.60-0.65$ \\
\hline 11 & B2N SHEET & SODA LIME & 0.120 & & 0.913 & & 70 & 38 & & \\
\hline
\end{tabular}

1) APPROXIMATE COST DERIVED FROM DEMAND/PRODUCTION ESTIMATES IN FEBRUARY-MAY 1978. ACTUAL COSTS MAY BE SUBJECT TO LARGE FLUCTUATIONS.

2) NORMAL HEMISPHERICAL TRANSMITTANCE OF SPLIT AND FLATIENED TUBING PROVIDED BY R. B. PETTIT, SANDIA LABORATORIES, ALBUQUERQUE.

3) ESTIMATED OPTICAL FIGURE BASED ON MEASUREMENTS OF OTHER ROLLED TWIN GROUND SAMPLES AND MANUFACTURER CLAIMS.

4) \$0.31 QUOTED IN RESPONSE TO DOE SOLICITAIION ET 78-B-03-2221

5) \$1.66 QUOTED IN RESPONSE TO DOE SOLICITATION ET 78-8-03-2221 6) \$0.49 QUOTED IN RESPONSE TO DOE SOLICITATION ET 78-B-03-2221

7) \$1.62 QUOTED IN RESPONSE TO DOE SOLICITATION ET 78-B-03-2221 


\section{FOREIGN SOURCES OF FLAT GLASS}

A letter requesting indication of interest in supplying flat glass samples was sent to 22 foreign glass manufacturers. Potential sources contacted are listed in Appendix C. A limited response was received.

Pilkington Brothers, Limited, England, replied on behalf of the Pilkington Group in the U.K., Australia, P.A.C.I., and Canada. Pilkington manufactures float glass at a nominal $0.11 \% \mathrm{Fe}_{2} \mathrm{O}_{3}$ level. They would onty have interest in producing low iron glass at volumes greater than a hundred million square feet.

Vidrio Plano, S.A., Mexico, replied that their $3 \mathrm{~mm}$ float has $90 \%$ transmission at a $0.119 \% \mathrm{Fe}_{2} \mathrm{O}_{3}$ level (this is much higher than expected). They cannot send samples or cost, but feel that their prices are in "the acceptable range."

Hubert Matheisen, Inc., Woodland Hills, California, is the U.S. representative for Glaverbil S.A., Brussels, Boussois S.A., Paris, and Flachglas A.G. Delog-Detag, Gelsendirchen. Samples and technical data are being forwarded.

Sklo Union, Czechoslovakia, requested further details on the required properties and basic purpose in order to comment on the inquiry.

Exprover, Belgium, replied in behalf of Saint-Gobain Industries. Exprover explained that Saint-Gobain Industries, one of the European concerns of Exprover, coordinates the export sales. They have developed and patented a low cost method for fastening heliostat mirrors. Exprover stated that the optical properties of their $3 \mathrm{~mm}$ float glass fully fulfills the requirements for the glass in heliostat mirrors. Detailed information and samples will be supplied upon request.

Jean Glaswerk Schott and Gen., Inc. sent a sample of Schott B-270 Water White sheet glass. In addition, information and samples of $\mathrm{SiO}_{2}$ coated glass with anti-glare coating will be sent directly from their DUF facility. Additional development is underway at both DUF and Mainz to increase the efficiency of these coatings. 
At the time of publication of this report, samples have been received from only one foreign manufacturer, Schott. It has been brought to our attention that a manufacturer of high quality low iron float glass exists in Spain. Further details are unknown. However, it appears that most foreign sources of flat glass offer no advantage over products obtained from domestic sources. 


\section{REFERENCES}

1 R. B. Pettit, "Summary of Reflector Materials Properties." Summary Report of the Solar Reflective Materials Technology Workshop, PNL-2763/UC-62, October, 1978.

2 P. Moon, "Proposed Standard Solar Radiation Curves for Engineering Use." Journal of the Franklin Institute 320:604, Table III, 1940.

3 J. Vitko, Jr., "Optical Studies of Second Surface Mirrors Proposed for Use in Solar Heliostats." SAND 78-8228, Apri1, 1978.

4 D. M. Sanders and L. L. Hench, "Environmental Effects of Glass Corrosion Kinetics." Ceramic Bulletin 52(9):662-669, 1973.

5 D. M. Sanders and L. L. Hench, "Mechanisms of Glass Corrosion." J. Am. Ceram. Soc. 56 (7):373-377, 1973.

6 H. V. Walters and P. B. Adams, "Effects of Humidity on the Weathering of Glass." J. Non-Crystalline Solids 10:183-199, 1975.

7 ASTM E228-66aT "Linear Thermal Expansion of Rigid Solids with a Vitreous Silica Dilatometer." Annual Book of ASTM Standards, Part 13, American Society for Testing and Materials, Philadelphia, Pennsylvania, p. 741 , 1971.

8 The Glass Industry Directory Issue 59(10), 1977-1978.

9 Fay V. Tooley, The Handbook of Glass Manufacture, Vol. II. Books for Industry, Inc., New York, New York, p. 712, 1974.

10 European Glass Directory and Buyers Guide, Fuel and Metallurgical Journals Ltd., 21 John Adams Street, London, England WCZN. 6JH (1977). 
- 


\section{APPENDIX A}

Calculations of Reflectance and Transmittance for Glass and Second Surface Mirrors 


\section{APPENDIX A \\ CALCULATIONS OF REFLECTANCE AND TRANSMITTANCE FOR \\ GLASS AND SECOND SURFACE MIRRORS}

Consider an absorbing material with two air-to-material interfaces as illustrated in Figure Al. The index of refraction of the material determines the first surface reflection at a particular wavelength.

$$
R(\lambda)=\left(\frac{n(\lambda)-1}{n(\lambda)+1}\right)^{2}
$$

Define an internal transmittance of the material $X$ which is dependent on the thickness of the material, the magnitude of the absorption coefficient, and the concentration of the absorbing species. Then at each interface

$$
I=T+R
$$

where $I$ is the incident power, $T$ is the transmitted power and $R$ is the reflected power.

The following series of expressions can be easily derived assuming $I_{1}=1$ :

$$
\begin{aligned}
& R_{1}=R \\
& T_{1}=1-R \\
& I_{2}=(1-R) X \\
& R_{2}=(1-R) X R \\
& T_{2}=(1-R)^{2} X
\end{aligned}
$$




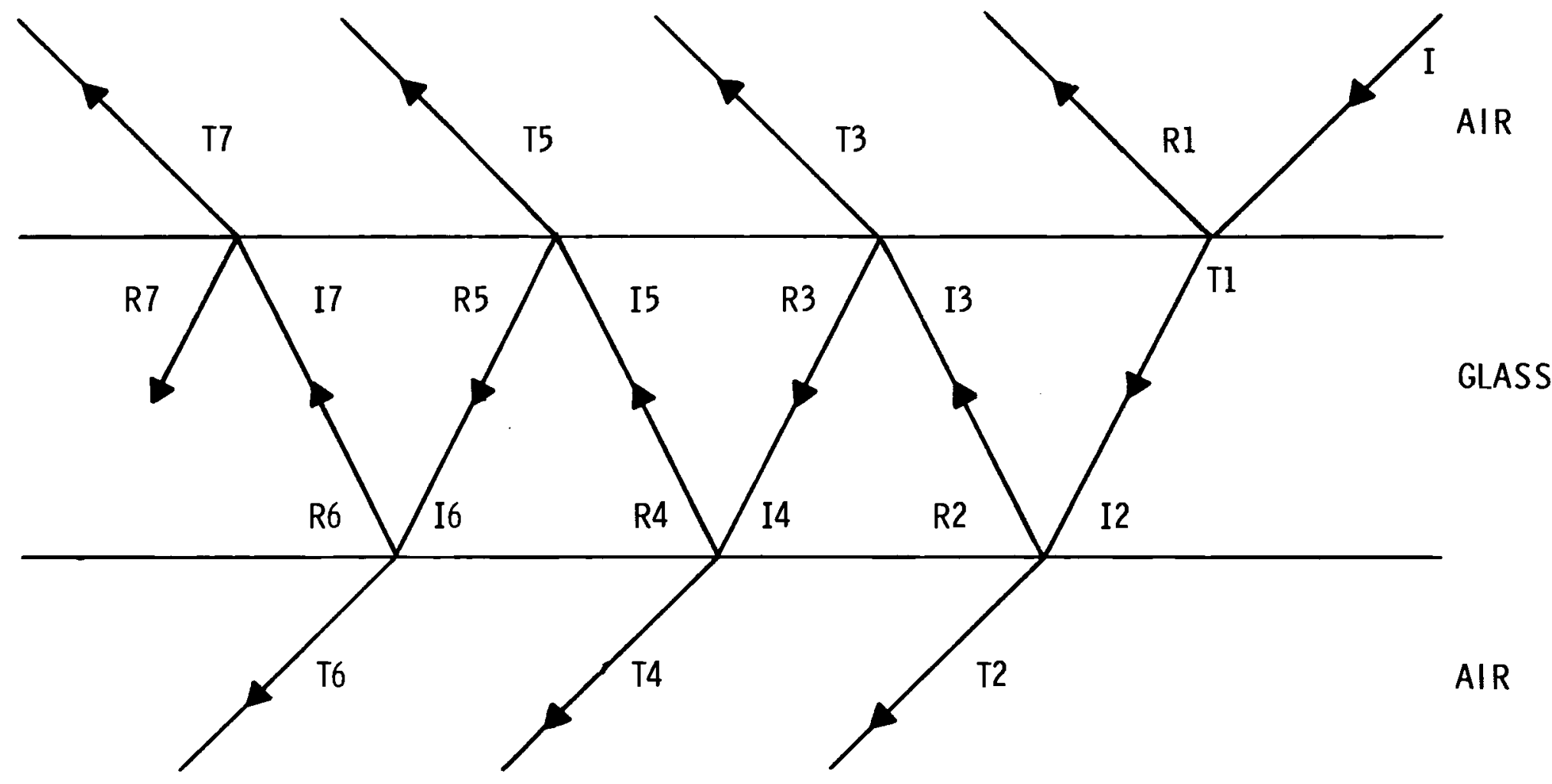

FIGURE A1. Air-Glass-Air Interreflection Geometry 


$$
\begin{aligned}
& I_{3}=(1-R) x^{2} R \\
& R_{3}=(1-R) x^{2} R^{2} \\
& T_{3}=(1-R)^{2} x^{2} R \\
& I_{4}=(1-R) x^{3} R^{2} \\
& R_{4}=(1-R) x^{3} R^{3} \\
& T_{4}=(1-R)^{2} x^{3} R^{2} .
\end{aligned}
$$

The total reflectance from the material is then

$$
\begin{aligned}
R_{T} & =R_{1}+T_{3}+T_{5}+T_{7} \ldots \\
& =R+\chi^{2} R(1-R)^{2}+(1-R)^{2} \chi^{4} R^{3} \\
& +(1-R)^{2} \chi^{6} R^{5}+\ldots
\end{aligned}
$$

This expression can be simplified by noting that

$$
\frac{\left(\frac{R_{T}}{\frac{R}{\chi^{2}}-1}\right)-1-2 R}{R}=R_{T} .
$$

Solving for $R_{T}$ we find

$$
R_{T}=\frac{R}{1-R^{2} x^{2}}\left(1-x^{2}-2 R\right) .
$$


Similarly the total transmittance becomes

$$
\begin{aligned}
T_{T} & =T_{2}+T_{4}+T_{6}+\ldots \\
& =x(1-R)^{2}+x^{3} R^{2}(1-R)^{2}+x^{5} R^{4}(1-R)^{2}+\ldots
\end{aligned}
$$

This can be simplified by noting that

$$
\chi^{2} R^{2} T_{T}+\chi(1-R)^{2}=T_{T} .
$$

Solving for $T_{T}$ we find

$$
T_{T}=\frac{(1-R)^{2} X}{1-x^{2} R^{2}} .
$$

In the case of a second mirror, the total reflectance can be found in the same manner. First assume that the glass to metal interface has a reflectance $R_{M}$. Then

$$
\begin{aligned}
& R_{1}=R \\
& T_{3}=(1-R) x^{2} R_{M} \\
& T_{5}=(1-R)^{2} x^{4} R_{M}{ }^{2} R \\
& T_{7}=(1-R)^{2} \chi^{6} R_{M}{ }^{3} R^{2} .
\end{aligned}
$$

Thus, the total reflectance for the mirror becomes 


$$
\begin{aligned}
R_{T M}=R & +T_{3}+T_{5}+T_{7}+\ldots \\
=R & +(1-R)^{2} \times{ }^{2} R_{M}+(1-R)^{2} \times{ }^{4} R_{M}{ }^{2} R \\
& +(1-R)^{2} \times{ }^{6} R_{M}{ }^{3} R^{2}+\ldots
\end{aligned}
$$

This can be simplified by noting that

$$
\frac{\frac{\left(R_{T M}-R\right.}{x^{2} R_{M}}-1+2 R}{R}=R_{T M} .
$$

Solving for $R_{T M}$ we find

$$
R_{T M}=\frac{R+x^{2} R_{M}-2 R x^{2} R_{M}}{1-x^{2} R_{M} R} .
$$


.

, 
APPENDIX $B$

CALCULATION OF THE IMPACT OF GLASS FLATNESS ON RECEIVER DIMENSIONS 
APPENDIX B

CALCULATION OF THE IMPACT OF GLASS

FLATNESS ON RECEIVER DIMENSIONS

The following calculations estimate the required receiver aperture for various systems with one scattering reflection between the source and the receiver. Several assumptions are made to simplify the calculations. These assumptions are:

- The radial solar intensity distribution is assumed to be a constant as a function of angular aperture up to half angle of $4.75 \mathrm{mrad}$ and zero thereafter. This distribution is not an accurate representation but it does provide a conservative estimate of the source.

- The glass mirror is a symmetric one-dimensional scatterer. This is a characteristic of the glass examined in this report.

- The mirror scattering distribution has a maximum half angle, $\Theta_{M}$, within which all the energy is contained. This is also characteristic of the glasses that were examined.

The two-dimensional power distribution of the solar disk can be reduced to one dimension to simplify the calculation. The differential power of the uniform solar disk as a function of the angular aperture, $\theta$, is

$$
\frac{d P}{d \theta}=2 I_{0} l^{2} \theta_{0} \sqrt{1-\left(\frac{\theta}{\theta_{0}}\right)^{2}}
$$

where $I_{0}$ is the intensity, $\theta_{0}$ is the half angle of the disk $(4.75 \mathrm{mrad})$, and $\ell$ is the source to receiver distance.

In the case where the mirror is interjected into the optical path as an intermediate scatterer between the source and the receiver, the power distribution at the receiver can be found by the convolution

$$
P(\theta)=f_{1}(\theta) \star f_{2}(\theta)=\int_{-\infty}^{\infty} f_{1}\left(\theta^{1}\right) f_{2}\left(\theta-\theta^{1}\right) d \theta^{1}
$$


Here $f_{1}$ is the solar distribution and $f_{2}$ is the scattering function of the mirror.

Analytical solutions have been calculated for two mirror scattering functions. The most conservative solution uses a square shaped scattering distribution in which

$$
\begin{aligned}
f_{1}(\theta) & =\left.\frac{1}{2 \theta_{m}}\right|_{-\theta_{m}} ^{\theta_{m}} \text { and } \\
& =0 \theta<-\theta_{m} \text { and } \theta>\theta_{m} .
\end{aligned}
$$

In relation to the curves in Figures 8 and 9, this distribution corresponds to a straight line drawn from 1.0 on the vertical area axis to the point, $\theta_{m}$, where the curve intercepts the horizontal angle axis. In all the glass samples evaluated except the Fourco plate glass, this distribution represents a conservative estimate of the scattering function.

Performing the convolution integral for the square scattering distribution, we find

$$
P(\theta)_{0}=\left(\frac{\theta+\theta_{m}}{\theta_{0}}\right) \sqrt{1-\left(\frac{\theta+\theta_{m}}{\theta_{0}}\right)^{2}}+\sin ^{-1}\left(\frac{\theta+\theta_{m}}{\theta_{0}}\right)+\frac{\pi}{2}
$$

for the interval $-\theta_{0}-\theta_{m}<\theta<-\theta_{0}+\theta_{m}$, and

$$
\begin{aligned}
P(\theta)_{\square} & =\left(\frac{\theta+\theta_{m}}{\theta_{0}}\right) \sqrt{1-\left(\frac{\theta+\theta_{m}}{\theta_{0}}\right)^{2}}-\left(\frac{\theta-\theta_{m}}{\theta_{0}}\right) \sqrt{-\left(\frac{\theta-\theta_{m}}{\theta_{0}}\right)^{2}} \\
& +\sin ^{-1}\left(\frac{\theta+\theta_{m}}{\theta_{0}}\right)-\sin ^{-1}\left(\frac{\theta-\theta_{m}}{\theta_{0}}\right)
\end{aligned}
$$


for the interval $-\theta_{0}+\theta_{m}<\theta<\theta_{0}-\theta_{m}$, and

$$
P(\theta)_{0}=0
$$

for $\theta<\theta_{0}-\theta_{m}$

From the above expressions a series of integral bias curves can be developed which represent the fraction of the available power received versus receiver aperture, $\Theta_{A}$, for a particular maximum scattering angle, $\theta_{m}$.

Here the integral bias curves are defined as

$$
I B C=\frac{\int_{0}^{\theta} P(\theta) d \theta}{\int_{0}^{\infty} P(\theta) d \theta} .
$$

Finally, plots of the required receiver aperture, $\theta_{A}$, versus maximum scattering angle $\Theta_{m}$ can be developed from this family of integral bias curves. Figure $B 1$ shows these curves of the maximum aperture required in the scattering direction to intercept 90, 95, 98, and 100 percent of the available power versus $\theta_{m}$. The curves show that for a mirror with maximum scattering half angle of $2.5 \mathrm{mrad}, 95 \%$ of the energy is contained within a receiver aperture that has $5.25 \mathrm{mrad}$ radius or is $10.5 \mathrm{mrad}$ wide. Thus, since only one dimensional scattering is considered, the receiver aperture would have to be $9.5 \times 10.5 \mathrm{mrad}$ and properly oriented to intercept $95 \%$ of the energy.

If one assumes a triangular distribution for the scattering function of the mirror, then the convolution integral yields

$$
\begin{aligned}
P(\theta)_{0} & =\frac{1}{2} \frac{\theta_{m}+\theta}{\theta_{0}}\left[\left(\frac{\theta_{m}+\theta}{\theta_{0}}\right) \sqrt{\left.1-\left(\frac{\theta+\theta_{m}}{\theta_{0}}\right)^{2}+\sin ^{-1}\left(\frac{\theta+\theta_{m}}{\theta_{0}}\right)+\frac{\pi}{2}\right]}\right. \\
& +\frac{1}{3}\left(1-\left(\frac{\theta^{+\theta_{m}}}{\theta_{0}}\right)^{2}\right)^{\frac{3}{2}}
\end{aligned}
$$




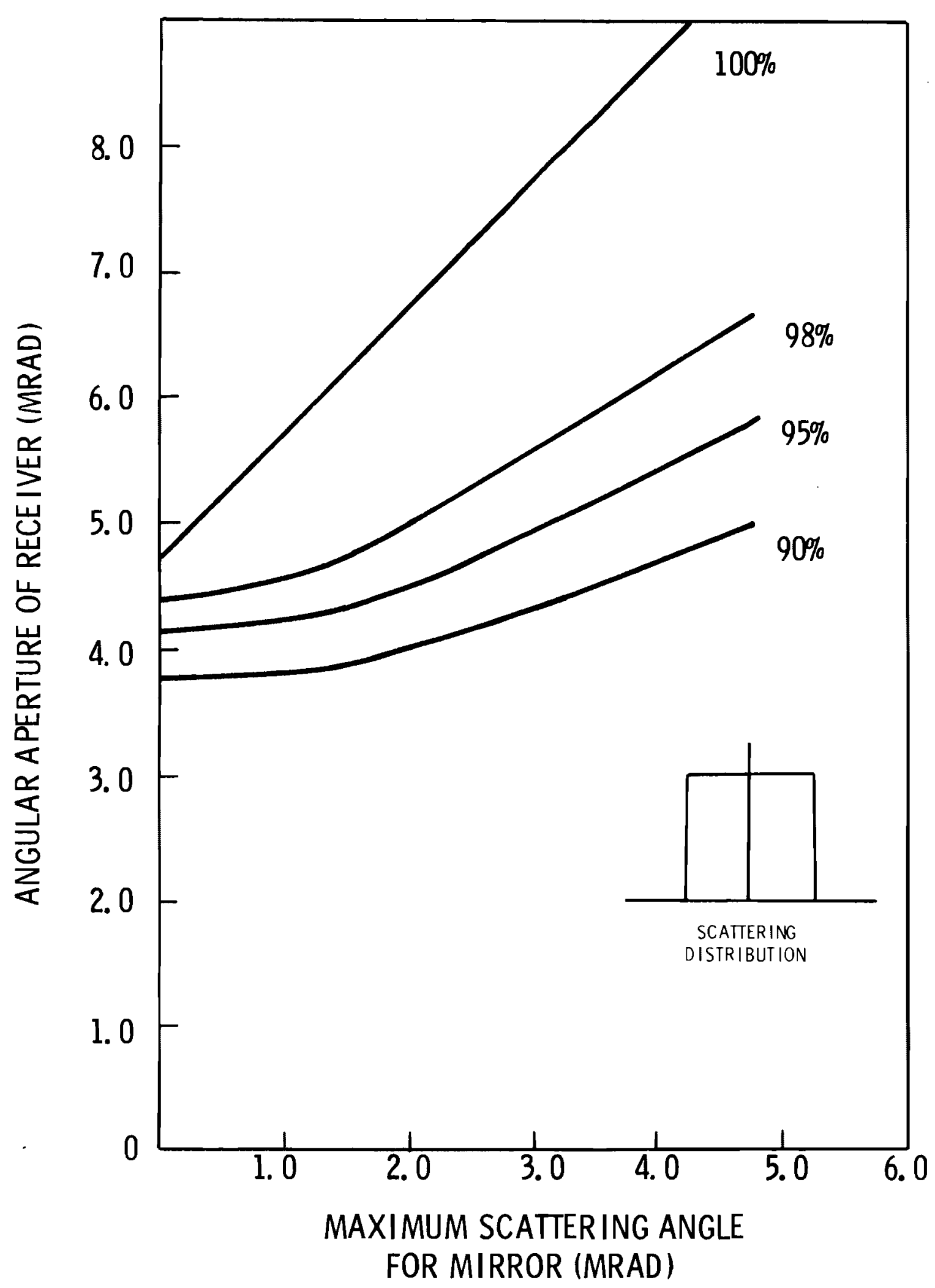

FIGURE B1. Half Angle of Receiver Aperture Required to Intercept Various Amounts of Power from Mirrors with a Rectangular Scattering Function 
for the interval $-\theta_{0}-\theta_{m}<\theta<-\theta_{0}$, and

$$
\begin{aligned}
P(\theta)_{\triangle} & =\frac{\theta^{2}}{\theta_{0} 2} \sqrt{1-\frac{\theta^{2}}{\theta^{2}}}+\frac{1}{2}\left(\frac{\theta+\theta_{m}}{\theta_{0}}\right)^{2} \sqrt{1-\left(\frac{\theta+\theta_{m}}{\theta_{0}}\right)^{2}}-\frac{\theta}{\theta_{0}} \sin ^{-1}\left(\frac{\theta}{\theta_{0}}\right) \\
& +\left(\frac{\theta+\theta_{m}}{2 \theta_{0}}\right) \sin ^{-1}\left(\frac{\theta+\theta_{m}}{\theta_{0}}\right)-\frac{\theta}{\theta_{0}} \sin ^{-1}\left(\frac{\theta}{\theta_{0}}\right)+\left(\frac{\theta+\theta_{m}}{2 \theta_{0}}\right)^{-1} \sin ^{-1}\left(\frac{\theta+\theta_{m}}{\theta_{0}}\right) \\
& +\frac{\left(\theta_{m}-\theta\right)}{4 \theta_{0}}+\frac{1}{3}\left(1-\left(\frac{\theta+\theta_{m}}{\theta_{0}}\right)^{2}\right)^{\frac{3}{2}}-\frac{2}{3}\left(1-\left(\frac{\theta}{\theta_{0}}\right)^{2}\right)^{\frac{3}{2}}
\end{aligned}
$$

for the interval $-\theta_{0}<\theta<-\theta_{0}+\theta_{m}$, and

$$
\begin{aligned}
P(\theta)_{0}= & -\frac{\theta^{2}}{\theta 2} \sqrt{1-\frac{\theta^{2}}{\theta_{0}^{2}}}+\frac{1}{2}\left(\frac{\theta+\theta_{m}}{\theta_{0}}\right)^{2} \sqrt{1-\left(\frac{\theta+\theta_{m}}{\theta_{0}}\right)^{2}}+\frac{1}{2}\left(\frac{\theta_{m}-\theta}{\theta_{0}}\right)^{2} \sqrt{1-\left(\frac{\theta-\theta_{m}}{\theta_{0}}\right)^{2}} \\
& -\frac{\theta}{\theta_{0}} \sin ^{-1}\left(\frac{\theta}{\theta_{0}}\right)-\left(\frac{\theta_{m}-\theta}{2 \theta_{0}}\right) \sin ^{-1}\left(\frac{\theta-\theta_{m}}{\theta_{0}}\right)+\frac{\theta+\theta_{m}}{2 \theta_{0}} \sin ^{-1}\left(\frac{\theta+\theta_{m}}{\theta_{0}}\right) \\
& -\frac{2}{3}\left(1-\left(\frac{\theta}{\theta_{0}}\right)^{2}\right)^{\frac{3}{2}}+\frac{1}{3}\left(1-\left(\frac{\theta-\theta_{m}}{\theta_{0}}\right)^{2}\right)^{\frac{3}{2}}+\frac{1}{3}\left(1-\left(\frac{\theta+\theta_{m}}{\theta_{0}}\right)^{2}\right)^{\frac{3}{2}}(B 10)
\end{aligned}
$$

for the interval $-\theta_{o}+\theta_{m}<\theta_{0}<\theta_{o}-\theta_{m}$, and

$$
P(\theta)_{\square}=0
$$

for $\theta<-\theta_{c}-\theta_{m}$.

Again, the curves of required aperture versus maximum scattering angle can be generated from the integral bias curves as shown in Figure B2.

It can be demonstrated that the actual scattering functions for the glass that was characterized lie somewhere between the triangular and rectangular distributions which were assumed for the previous calculations. As more detailed scattering information becomes available and the receiver constraints solidify, more detailed calculations may be justifiable. 


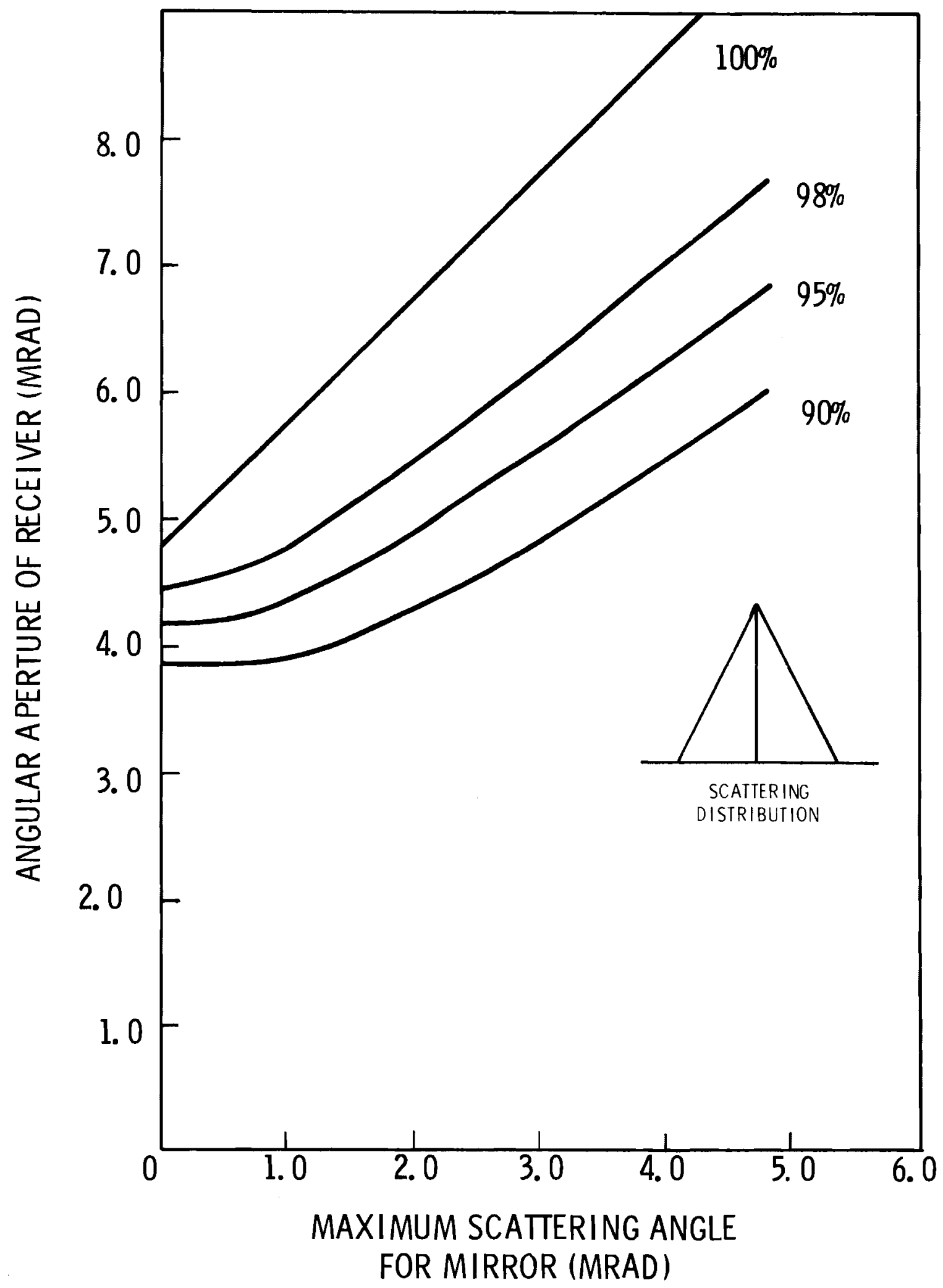

FIGURE B2. Half Angle of Receiver Aperture Required to Intercept Various Amounts of Power from Mirrors with a Triangular Scattering Function 


\section{APPENDIX C}

FOREIGN MANUFACTURERS CONTACTED AS POSSIBLE SOURCES OF FLAT GLASS*

*Sources obtained from references (8), (9), and (10). 
APPENDIX C

FOREIGN MANUFACTURERS CONTACTED AS

POSSIBLE SOURCES OF FLAT GLASS

Nippon Sheet Glass Co. Ltd.

8-4-Chome, Doshomachi

Nigashi-Ku, Osaka, Japan

Central Glass Co. Ltd.

Kowa-Hitotsubashi Bldg., 7 ,

Kanda-Nishiricho 3 Chome

Chiyoda-Ru Tokyo 101, Japan

Saint-Gobain Industries

62 Boulevard Victor-Hugo

P.0. Box 124

92209 Neuilly-Sur-Seince, France

Exprover S.A.

Parc Seny, Rue Charles Lemaire, 1

Boite No. 7, 1160 Brussels, Belgium

Pilkington Aci Limited

470 Collins Street

Melbourne, Victoria

3000 , Australia

Flachglas Ag Delog-Detag

650 Gelsenkirchen-Rotthausen,

Auf der Reihe 2,

Postfach 669, Germany

Australian Consolidated Industries Ltd. 550 Bourke Street

Melbourne, Victoria

3000 , Australia

Erste Osterreichische

Maschinglasind. Ag

2345 Brunn/Gebirge,

P.0. Box 9,

Austria

Pilkington Glass Ltd.

101 Richmond Street West

Toronto M5H 1V9, Ont., Canada
Asahi Glass Co. Ltd.

1-2, Marunoichi 2-Chome,

Chiyoda-Ku, Tokyo 100, Japan

BSN-Gervais Danone

Boussois Souchon Neuvesel

22, Bd Malesherbes

Paris 8, France

Jena Glaswerk Schott \& Gen, Inc.

11 East 26th Street

New York, NY 10010

Glaverbel S.A.

Chaussee de la Hulpe 166

B-1170

Brussels, Belgium

Glaceries de St. Roch S.A.

Exprover S.A.

Avenue Louis 430

B-1050

Brussels, Belgium

Glaces de Boussois

22 Boulevard Malesherbes

Paris 8, France

Compagnie de Saint Gobain

Fabrica Pisana

Via Aurelia \#1

56100

Pisa, Italy

Cristaleria Espanola S.A.

Almagro 42

Madred 4, Spa in

SkTo Union

N.P.

Teplice - Retenice

Czechos lovakia 
Pilkington Brothers Ltd.

St. Helens, Merseyside, WA10 3TT England

Plano, Vidrio, S.A.

Escobedo Nte. 1735

P.0. Box 372

Monterrey, N.L. Mexico 75-16-95
Vidrierias de Uodio S.A.

Carmen 20

Llodio, Alava, Spain

Cristales Curvados S.A.

Diputacion 172

Barcelona, 11, Spain 


\section{APPENDIX D}

SPECIFICATION FOR FLAT GLASS FOR CENTRAL RECEIVER HEL IOSTAT APPL ICATIONS 


\section{APPENDIX D \\ SPECIFICATION FOR FLAT GLASS FOR CENTRAL RECEIVER HELIOSTAT APPLICATIONS}

\section{Juty 26, 1978 \\ SPECIFICATIONS FOR PILOT PLANT HELIOSTAT GLASS}

1. SCOPE

1.1 This specification applies to glass used as the primary transparent substrate for second surface mirrors on heliostats for central power tower solar conversion concepts.

1.2 The specification reflects the specific requirements placed on the glass for the Barstow Ten Megawatt Solar Pilot Plant Facility.

2. APPLICABLE PUBLICATIONS

2.1 The following publications have been used extensively in the preparations of this specification:

2.1.1 Federal Specification for Glass, Float or Plate, Sheet, and Figured (Flat, for Glasing Mirrors and other uses). DD-G-451D, Apri1 25, 1977.

2.1.2 Canadian Government Specifications Board Standard for Glass, Polished Plate or Float, Flat, Clear. CAN12.3-M76, August 1976.

2.1.3 American Society for Testing and Materials (ASTM) C162 Definition of terms relating to Glass and Glass Procedures.

3. REQUIREMENTS

3.1 General Requirements - minimum acceptable.

3.1.1 Total Solar Energy Transmittance (TSET) $>0.88$

3.1.2 Effective Figure (Flatness)
(A) $90 \%$ of 1 ight area
$\leq 1.5 \mathrm{mrad}$
(B) $99 \%$ of 1 ight area
$<2.5 \mathrm{mrad}$

3.1.3 Thermal Coefficient of Expansion
$8.5-10.0 \times 10^{-6} /{ }^{\circ} \mathrm{C}$
$\left(4.7-5.5 \times 10^{-6} /{ }^{\circ} \mathrm{F}\right)$ 
3.1.4 Residual Stress $<1.4 \mathrm{MPa} \quad(<200 \mathrm{psi}) \quad$ (n)

3.1.5 Solarization shall not reduce TSET to below (k) minimum acceptable level of $\geq 0.88$.

3.1.6 Corrosion resistance of glass to weathering shall be sufficient such that TSET does not fall below minimum acceptable level of $\geq 0.88$.

3.2 Dimensions - a11 lights score and cracked to size

$\begin{array}{llll}3.2 .1 & \text { Width and Length } & 1.08 \mathrm{~m} \times 2.85 \mathrm{~m} & \left(42.5 \times 116^{\prime \prime}\right) \\ 3.2 .2 & \text { Size Tolerance } & \pm 1.6 \mathrm{~mm} & \left( \pm 0.062^{\prime \prime}\right) \\ 3.2 .3 & \text { Thickness } & 2.4-3.3 \mathrm{~mm} & \left(0.095-0.130^{\prime \prime}\right) \\ 3.2 .4 & \text { Thickness Variation } & <0.25 \mathrm{~mm} / \mathrm{m} & (<0.003 \mathrm{in} / \mathrm{ft}) \\ 3.2 .5 & \text { Squareness } & 3.0 \mathrm{~mm} & \left(0.12^{\prime \prime}\right) \\ 3.2 .6 \text { Bevel } & 0.8 \mathrm{~mm} & \left(0.03^{\prime \prime}\right) \\ 3.2 .7 \text { Corners on and 0ff } & 3.2 \mathrm{~mm} & \left(0.12^{\prime \prime}\right)\end{array}$

3.3 Bulk and Surface Defects - maximum acceptable limits

\begin{tabular}{|c|c|c|c|c|}
\hline 3.3 .1 & Gaseous Inclusions & $6.5 \mathrm{~mm}$ & $\left(0.25^{\prime \prime}\right)$ & $(a, e, f, g)$ \\
\hline 3.3 .2 & $\begin{array}{l}\text { Open Gaseous } \\
\text { Inclusions }\end{array}$ & $3.0 \mathrm{~mm}$ & $\left(0.12^{\prime \prime}\right)$ & $(a, e, g, i)$ \\
\hline 3.3 .3 & Knots & $3.0 \mathrm{~mm}$ & $\left(0.12^{\prime \prime}\right)$ & $(a, e, g, i)$ \\
\hline 3.3 .4 & Stones & $1.5 \mathrm{~mm}$ & $\left(0.06^{\prime \prime}\right)$ & $(a, e, g, i)$ \\
\hline 3.3 .5 & Crush & Heavy, $6.5 \mathrm{~mm}$ & $\left(0.25^{\prime \prime}\right)$ & $(a, d, i)$ \\
\hline 3.3 .6 & Scratches & Medium & & $(a, d, i)$ \\
\hline 3.3 .7 & Rubs & Heavy & & $(a, d, i, h)$ \\
\hline 3.3 .8 & Digs & $6.5 \mathrm{~mm}$ & $\left(0.25^{\prime \prime}\right)$ & $(a, g, i)$ \\
\hline 3.3 .9 & $\begin{array}{l}\text { Ream, String, Lines } \\
\text { Wave }\end{array}$ & $90^{\circ}$ VIA, Heavy & & $(b, c)$ \\
\hline 3.3 .10 & Dirt & Clean & & (0) \\
\hline
\end{tabular}

3.4 Edge Defects - maximum acceptable limits for edge defects. The lights shall be edge cut at the factory.
3.4.1 Flake Chip
$3.0 \mathrm{~mm}$
$\left(0.12^{\prime \prime}\right)$
3.4.2 Flares
$1.5 \mathrm{~mm}$
$\left(0.06^{\prime \prime}\right)$
3.4.3 Vee Chips and Checks NONE 


\subsection{Preparation for Delivery}

3.5.1 Edge defects: The specifications in Section 3.4 shall apply.

3.5.2 Packaging, labeling and storage of glass lights shall be according to good commercial practice.

4. FOOTNOTES

(a) Separate by at least $0.3 \mathrm{~m}\left(12^{\prime \prime}\right)$.

(b) Vision interference angle for examination of Ream, String, and Wave is determined by placing the sample in a vertical position at a distance of approximately $1 \mathrm{~m}$ (39") from a background showing essentially straight parallel lines. The viewer looks through the sample from a distance of approximately $1 \mathrm{~m}$ (39") using a background light suitable for observing each type of defect. The line of vision shall be perpendicular to the background. The sample is viewed at an angle to the surface of not less than the specified vision interference angle. Slight movements of the head horizontally through an angle of two to three degrees will make waves or lines more perceptible.

(c) Intensity - Ream, String and Wave. When evaluated using the shadowgraph method described below, the intensity is defined as having readouts at distances greater than or equal to the following:

\begin{tabular}{ll} 
Intensity & Minimum Distance \\
\cline { 2 - 3 } & $75 \mathrm{~mm}\left(3^{\prime \prime}\right)$ \\
Medium & $50 \mathrm{~mm}\left(2^{\prime \prime}\right)$ \\
Heavy & $25 \mathrm{~mm}\left(1^{\prime \prime}\right)$
\end{tabular}

The shadowgraph method uses a projector with a 500 watt 1 amp and an objective lens with an approximate $5 \mathrm{~cm}\left(2^{\prime \prime}\right)$ aperture and an approximate $30 \mathrm{~cm}\left(12^{\prime \prime}\right)$ focal length to focus the light on a flat white projection screen positioned $7.6 \mathrm{~m}\left(25^{\prime}\right)$ from the light source in a dark room. The glass is placed in a vertical position parallel to the screen between the light and the screen. The glass is moved slowly toward the screen with a vertical oscillating motion. The shadowgraph readout is the distance at which the distortion just blends with the general shadow of the glass on the screen. 
(d) Intensity - Scratches, Rubs and Crush. When looking through the glass and perpendicular to it, using daylight without direct sunlight or with a background light suitable for observing each type of defect, the defects shall not be detectable when viewed at the following distances:

\begin{tabular}{lc} 
Intensity & Minimum Distance \\
\cline { 2 - 2 } & $0.2 \mathrm{~m}\left(9^{\prime \prime}\right)$ \\
Light & $1.0 \mathrm{~m}\left(39^{\prime \prime}\right)$ \\
Medium & $3.0 \mathrm{~m}\left(10^{\prime}\right)$ \\
Heavy & $>3.0 \mathrm{~m}\left(10^{\prime}\right)$
\end{tabular}

(e) For elongated defects, the maximum size specified shall be determined by adding the length and the width of the defect and dividing by two: $(L+W) / 2$.

(f) For defects of small size or less intensity, the minimum separation may be proportionally less. The larger of the two defects shall govern separation. Defects not specifically mentioned shall be compared to the defect they most closely resemble.

(g) Sharp edges, fissures, sma11 cracks, chips or other imperfections on the surface of the glass which may result in high internal stress at or near the defect are not acceptable.

(h) In no case shall more than $0.1 \%$ of the total surface area of the light be affected by the combined area of al1 defects.

(i) The defects cannot destroy the pristine surface of the glass to an extent that will adversely affect the strength of the glass or result in spontaneous fracture during its anticipated thirty-year service life.

(j) The effective figure of the glass light used in mirror applications shall be determined by a laser raytrace technique. The peak to peak deviation of the second surface reflection shall be used as the acceptance criterion. The measurement shall be performed using a 6328 \& 1 aser beam with a diameter between $1 \mathrm{~mm}$ and $3 \mathrm{~mm}(0.04-$ 0.12 in.) incident at $45^{\circ}$ to the first surface of the glass 
specimen. The glass may be supported by a flat horizontal table for the measurement, but the glass light cannot be forced to conform to the shape of the table except under its own weight. A one milliradian correction to the data every $30 \mathrm{~cm}$ (12") is permitted to allow for overall bow or warp in the glass light.

(k) The minimum total solar energy transmittance (TSET) requirement shall apply over $99.9 \%$ of the entire surface area of the 1 ight. This requirement applies to the glass as received and includes the effects of any bulk or surface defects produced during the manufacturing and handling process.

(1) Edge defects which may result in spontaneous fracture of the light during its expected 30-year lifetime are not acceptable.

(m) Thermal coefficient of expansion in the linear expansion of the glass per unit length per degree temperature rise over the range of $-30^{\circ} \mathrm{C}$ to $+50^{\circ} \mathrm{C}\left(-10^{\circ} \mathrm{F}\right.$ to $\left.+120^{\circ} \mathrm{F}\right)$.

(n) Residual stress to be determined by quartz wedge or laser measurements.

(0) The glass surface must be cleanable by non-abrasive means to the extent required for silvering.

5. DEFINITIONS

Bevel - The difference in length between the upper and lower surface of the glass at the edge after cutting.

Bubbles - Gas inclusions in any glass. These inclusions are almost always brilliant in appearance. The term is applied to all such inclusions larger than $1.0 \mathrm{~mm}$ in maximum dimension. The term "smal1 bubbles" refers to sizes between 1.0 and $2.5 \mathrm{~mm}$ (see "Seeds").

Check - An imperfection or surface crack in the glass.

Cords (see "Ream") - Heavy strings incorporated in the sheet rather than on the surface, occurring without any regularity of direction and appearing to be of considerable thickness.

Corner On and Off - Glass chipped off remaining on the corners due to imperfect cutting. 
Crush - A lightly pitted area resulting in a dull gray appearance over the region.

Digs - Deep, short scratches.

Dirt - A small particle of foreign matter imbedded in or adhered to the glass surface.

Effective Figure - the exact effective optical shape of the glass as measured against a theoretical "perfect" shape. The effective figure of a glass second surface mirror is a result of the actual surface figure of both surfaces of the glass as well as any index variations within the glass.

Flake Chips - Seashe11-1ike fracture of the surface at the edge of the glass sheet caused by the cutting process.

Flare - An extension of glass remaining or absent from the surface after breaking during the cutting process.

Gaseous Inclusions - Round or elongated bubbles in the glass.

Knot - A transparent area of incompletely assimilated glass having an irregular knotty or tangled appearance.

Lines - Fine cords or strings, usually on the surface of sheet glass. Waves that extend continuously across the sheet so that the reflection from the surface appears as a line or series of lines extending either the full width or a considerable distance across the sheet.

Open Gaseous Inclusions - Bubbles at the surface of glass that are open, leaving a cavity in the finished surface.

Ream (see "Cords") - Inclusions within the glass, or layers of strings of glass, that are not homogeneous with the main body of the glass. An area of unhomogeneous glass incorporated in the sheet, producing a wavy appearance.

Residual Stress - The average tensile stress remaining in the glass after manufacture.

Rubs - Abrasion of the glass surfaces, producing a frosted appearance. A rub differs from a scratch in having appreciable width. 
Scratches - Any marking or tearing of the surface appearing as though it had been done by either a sharp or rough instrument. Scratches occur on glass in all degrees from various accidental causes. A sleek is a hairline scratch. A crush or rub is a surface scratch or series of small scratches generally caused by handling.

Seeds - Minute bubbles less than $1.0 \mathrm{~mm}$ in diameter. Fine seeds are visible only upon close inspection, usually appearing as small specks, and are an inherent defect in the best quality of plate glass. Seeds about $1.0 \mathrm{~mm}$ in diameter are usually considered coarse seeds.

Squareness - The difference between the two corner-to-corner diagonals of a square or rectangular shape.

Stones - Any opaque or partially melted particle of rock, clay or batch ingredient embedded in the glass.

Strings (see "Ream") - Wavy, transparent lines appearing as though a thread of glass has been incorporated into the sheet.

Total Solar Transmittance - The calculated transmittance for solar energy derived from the measured value of the spectral transmittance of the glass and using the values for the spectral distribution of solar energy received at sea level by a surface perpendicular to the sun's rays through an air mass of two. (See Parry Moon, "Proposed Standard Solar-Radiation Curves for Engineering Use," Journal Franklin Institute, Volume 230, Page 604, Table III, 1940.)

Vee-Chip - Deep "V"-shaped chip at glass edge causing area of high stress. Visual Interference Angle (VIA) - The angle of orientation of the glass light with respect to the observer.

Wave - Defects resulting from irregularities of the surfaces of glass, making objects viewed at varying angles appear wavy or bent. 
, 
PNL -2868

UC -62

\section{DISTRIBUTION}

No. of

Copies

OFFSITE

1 DOE Chicago Patent Group 9800 South Cass Avenue Argonne, IL 60439

A. A. Churm

6 DOE Division of Solar Technology 20 Massachusetts Avenue Washington, DC 20545
M. U. Gutstein
G. M. Kaplan
J. Weissinger
L. Melamed
G. Braun
J. E. Rannels

1 DOE Office of Solar Application

20 Massachusetts Avenue Washington, DC 20545

S. L. Sargent

27 DOE Technical Information Center

(UC 62)

3 Jet Propulsion Laboratory 4800 Oak Grove Drive Pasadena, CA 91108

W. Carroll

M. Adams

G. Herrera

2 Sandia Laboratory

Box 5800

A1buquerque, NM 87115
R. Pettit
E. Beauchamp

No. of

Copies

OFFSITE

7 Sandia Laboratories Livermore, CA 94550
A. Skinrood
W. Wilson
C. Mavis
C. Pignolet
E. English
J. Vitko
W. Delemeter

4 Solar Energy Research

Institute

1536 Cole Blvd.

Golden, CO 80401

B. Butler

P. Call

K. Masterson

T. Coyle

1 C. R. Frownfelter PPG Industries, Inc. One Gateway Center Pittsburg, PA 15222

1 J. S. Herbert ASG Industries, Inc. P.0. Box 929 Kingsport, TN 37662

1 A. F. Shoemaker Corning Glass Works Corning, NY 14830

1 D. Wiley Guardian Industries Corp. 43043 W. Nine Mile Road Northville, MI 48167

1 T. Martin CE Glass Division 825 Hylton Rd. Pennsarken, NJ 08110 
DISTRIBUTION (contd.)

No. of

Copies

OFFSITE

1 H. R. Swift

Libby Owens Ford Company

Technical Center

1701 E. Broadway

Toledo, $\mathrm{OH} 43605$

$1 \quad$ P. Bender

Ford Motor Company

Glass Division

3000 Renaissance Center

P.0. Box 43343

Detroit, MI 48243

1. J. McVaney

Fourco Glass Company

P.0. Box 2230

Clarksburg, WV 26301

1 J. Schrauth

Jena Glaswerk Schott \& Gen., Inc.

11 East 26th Street

New York, NY 10010

1 Robert A. England

Martin Marietta

MS S0403

P.0. Box 179

Denver, C0 80201

1 Mrs. McHugh

Sanders Associates

95 Canal St., MS MER12-1214

Nashua, NH 03061

1 Eric Nelson

ACUREX Corporation

485 Clyde Avenue

Mountain View, CA 94042

1 Hyman Leggett

Hughes Aircraft Company

MS $X-122, B 1 d g .20$

Culver City, CA 90230
No. of

Copies

ONSITE

2 DOE Richland Operations Office

H. E. Ransom

R. Stewart

31 Pacific Northwest Laboratory

W. J. Coleman

K. Drumheller

H. L. Hampton

M. A. Lind (20)

J. M. Rusin

Publishing Coordination (2)

Technical Information 


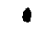

. 